\title{
Expression of an Activated Integrin Promotes Long-Distance Sensory Axon Regeneration in the Spinal Cord
}

\author{
Menghon Cheah, ${ }^{1}$ Melissa R. Andrews, ${ }^{2}$ DDaniel J. Chew, ${ }^{1}$-Elizabeth B. Moloney, ${ }^{3}$ Joost Verhaagen, ${ }^{3}$ \\ Reinhard Fässler, ${ }^{4}$ and James W. Fawcett ${ }^{1}$ \\ ${ }^{1}$ John van Geest Centre for Brain Repair, University of Cambridge, Cambridge CB2 0PY, United Kingdom, ${ }^{2}$ School of Medicine, University of St. Andrews, \\ St. Andrews KY16 9TF, United Kingdom, ${ }^{3}$ Laboratory for Neuroregeneration, Netherlands Institute for Neuroscience, 1105 BA, Amsterdam, The \\ Netherlands, and ${ }^{4}$ Department of Molecular Medicine, Max Planck Institute of Biochemistry, 82152 Martinsried, Germany
}

After CNS injury, axon regeneration is blocked by an inhibitory environment consisting of the highly upregulated tenascin-C and chondroitin sulfate proteoglycans (CSPGs). Tenascin-C promotes growth of axons if they express a tenascin-binding integrin, particularly $\alpha 9 \beta 1$. Additionally, integrins can be inactivated by CSPGs, and this inhibition can be overcome by the presence of a $\beta 1$-binding integrin activator, kindlin-1. We examined the synergistic effect of $\alpha 9$ integrin and kindlin-1 on sensory axon regeneration in adult rat spinal cord after dorsal root crush and adeno-associated virus transgene expression in dorsal root ganglia. After 12 weeks, axons from C6 - C7 dorsal root ganglia regenerated through the tenascin-C-rich dorsal root entry zone into the dorsal column up to $\mathrm{C} 1$ level and above ( $>25 \mathrm{~mm}$ axon length) through a normal pathway. Animals also showed anatomical and electrophysiological evidence of reconnection to the dorsal horn and behavioral recovery in mechanical pressure, thermal pain, and ladder-walking tasks. Expression of $\alpha 9$ integrin or kindlin-1 alone promoted much less regeneration and recovery.

Key words: adeno-associated virus; alpha9 integrin; axon regeneration; dorsal root ganglion; kindlin-1; spinal cord

\section{Significance Statement}

The study demonstrates that long-distance sensory axon regeneration over a normal pathway and with sensory and sensorymotor recovery can be achieved. This was achieved by expressing an integrin that recognizes tenascin- $\mathrm{C}$, one of the components of glial scar tissue, and an integrin activator. This enabled extensive long-distance $(>25 \mathrm{~mm})$ regeneration of both myelinated and unmyelinated sensory axons with topographically correct connections in the spinal cord. The extent of growth and recovery we have seen would probably be clinically significant. Restoration of sensation to hands, perineum, and genitalia would be a significant improvement for a spinal cord-injured patient.

\section{Introduction}

After injury, CNS axons fail to regenerate because of the presence of inhibitory factors, the lack of growth-promoting factors in

Received March 17, 2016; revised May 5, 2016; accepted May 30, 2016.

Author contributions: M.C., M.R.A., D.J.C., and J.W.F. designed research; M.C. performed research; E.B.M., J.V., and R.F. contributed unpublished reagents/analytic tools; M.C., M.R.A., D.J.C., and J.W.F. analyzed data; M.C. wrote the paper.

This work was supported by grants from the Christopher and Dana Reeve Foundation, the Medical Research Council, the European Research Council ECMneuro, and the Cambridge National Health and Medical Research Council Biomedical Research Centre.

J.W.F. is a paid consultant for Acorda Therapeutics and Novartis.

This article is freely available online through the J Neurosci Author Open Choice option.

Correspondence should be addressed to either of the following: Melissa R. Andrews, School of Medicine, Univer-

sity of St. Andrews, St. Andrews KY16 9TF, UK; or James W. Fawcett, John van Geest Centre for Brain Repair, University of Cambridge, Cambridge CB2 OPY, UK. E-mails: mra5@st-andrews.ac.uk, jf108@cam.ac.uk.

D0I:10.1523/JNEUROSCI.0901-16.2016

Copyright $\odot 2016$ Cheah et al.

This is an Open Access article distributed under the terms of the Creative Commons Attribution License Creative Commons Attribution 4.0 International, which permits unrestricted use, distribution and reproduction in any medium provided that the original work is properly attributed. the environment, and a poor intrinsic regenerative response of the neurons. In the injured CNS, extracellular matrix molecules, such as chondroitin sulfate proteoglycans (CSPGs) and tenascin- $\mathrm{C}$, are highly upregulated, and these molecules play a critical role in blocking CNS repair. The upregulated CSPGs in the glial scar have an inhibitory effect on axon growth, and treatments directly targeting CSPGs, such as chondroitinase, can permit some axon regeneration (Friedlander et al., 1994; Moon et al., 2001; Bradbury et al., 2002; Cafferty et al., 2007). Tenascin-C has several splice variants containing the binding sites for CSPGs, integrins, fibronectin, laminin, contactin, and other ligands (Joester and Faissner, 1999; Probstmeier and Pesheva, 1999; Lundell et al., 2004). The combination of CSPGs, tenascin-C, Nogo-A, semaphorin $3 \mathrm{~A}$, and other inhibitory molecules forms an inhibitory environment for axon regeneration (Milev et al., 1997; Probstmeier et al., 2000; Pasterkamp and Verhaagen, 2006; Kwok et al., 2014). Of these molecules, tenascin-C is of particular 
interest. It is thought of as an inhibitory molecule, but it can promote the growth of axons that possess an appropriate tenascin-binding integrin such as $\alpha 7 \beta 1$ or $\alpha 9 \beta 1$ (Mercado et al., 2004; Andrews et al., 2009). The aim of this study is to use a tenascin-binding integrin to promote spinal cord regeneration.

Integrins are a family of transmembrane cell adhesion receptors possessing an $\alpha$ and a $\beta$ subunit that can promote neurite outgrowth in embryonic (Lein et al., 1991; Neugebauer et al., 1991), postnatal (Vogelezang et al., 2001), and adult (Condic, 2001; Gardiner et al., 2005; Andrews et al., 2009) neurons. Although peripheral nerve regeneration is associated with upregulation of $\alpha 4, \alpha 5, \alpha 6, \alpha 7$, and $\beta 1$ (Hammarberg et al., 2000; Vogelezang et al., 2001; Ekström et al., 2003; Wallquist et al., 2004; Gardiner et al., 2007), $\alpha 9$ integrin, which is a receptor for tenascin-C, remains downregulated after CNS injury (Staniszewska et al., 2008; Andrews et al., 2009). The expression of $\alpha 9$ integrin in adult dorsal root ganglion (DRG) neurons promotes profuse sensory axon regeneration in vitro on tenascin (Andrews et al., 2009). However, the regeneration-promoting effect in vivo was modest after spinal cord injury and dorsal root crush. The reason is that integrins are deactivated by the presence of CSPGs and Nogo-A (Hu and Strittmatter, 2008; Tan et al., 2012).

Integrin activation, "inside-out" signaling, is controlled by the binding of kindlin and talin to the $\beta$-integrin cytoplasmic tail (Moser et al., 2009). This enables binding of a ligand to integrin, which triggers a series of intracellular signaling cascades, "outside-in" signaling. The kindlins comprise three isoforms (kindlin-1, kindlin-2, and kindlin-3) that bind to the $\beta$-integrin tail via a FERM (4.1/ezrin/ radixin/moesin) domain, triggering activation and cell-matrix adhesion (Rogalski et al., 2000). Kindlin-1 is expressed predominantly in epithelial cells, kindlin-2 is expressed in all tissues and is the only isoform expressed in the nervous system, and kindlin-3 is exclusively expressed in hematopoietic cells (Ussar et al., 2006). Our previous work has demonstrated that expression of kindlin-1, but not kindlin-2, can promote short-distance sensory axon regeneration in vivo in the presence of CSPGs (Tan et al., 2012).

The aim of this study was to examine whether the expression of the tenascin-binding $\alpha 9$ integrin with an integrin activator, kindlin-1, could promote extensive sensory axon regeneration in the spinal cord. We have examined sensory axon regeneration in vitro and in vivo from DRG neurons expressing $\alpha 9$ integrin and kindlin-1 through an environment rich in tenascin- $C$ and CSPGs. We show that activation of $\alpha 9$ integrin by kindlin 1 allows axons to interact with tenascin- $\mathrm{C}$ and overcome the inhibitory environment of the adult CNS. Extensive axon regeneration was observed in vivo through a mostly normal anatomical pathway with behavioral and physiological restoration of sensory functions. Expression of either $\alpha 9$ integrin or kindlin- 1 alone stimulated much less regeneration and recovery.

\section{Materials and Methods}

\section{Adult rat DRG cultures}

Adult female Sprague Dawley rats were killed, and DRGs were harvested. For explant culture, each DRG was cut into two to three pieces and then plated on substrate-coated glass coverslips. For dissociated culture, DRGs were incubated with $0.2 \%$ collagenase (Sigma) and $0.1 \%$ trypsin (Sigma), followed by trituration and centrifugation. Before being plated on substrate-coated glass coverslips at a density of $2.0-4.0 \times$ $10^{4}$ cells $/ \mathrm{cm}^{2}$, the cells were transfected with Neon transfection kit (Invitrogen). For each reaction, 500 ng of plasmid [ $\alpha 9$-enhanced yellow fluorescent protein (eYFP) and/or kindlin1-mCherry] was used to transfect $1.0-1.5 \times 10^{5}$ cells at $1200 \mathrm{~V}, 20 \mathrm{~ms}$, and two pulses. The substrates used for coating were poly-D-lysine ( $20 \mu \mathrm{g} / \mathrm{ml}$; Sigma), laminin (10 $\mu \mathrm{g} / \mathrm{ml}$; Sigma), tenascin-C (10 $\mu \mathrm{g} / \mathrm{ml}$; Millipore), or aggrecan $(10 \mu \mathrm{g} / \mathrm{ml}$; Sigma).

\section{Neurite outgrowth assay}

Dissociated cultures were maintained for $3 \mathrm{~d}$ and explant cultures for $5 \mathrm{~d}$ before fixation with $4 \%$ paraformaldehyde (PFA). Quantification was performed using NIH ImageJ. For dissociated cultures, the longest neurite of 20 randomly selected DRG neurons per condition was measured (five independent repeats to give 100 neurons). For explant cultures, the longest 25 neurites per explant per condition were measured (five explants per condition, five independent repeats). To measure the number of neurites extending from each explant, a parallel line was drawn $50 \mu \mathrm{m}$ away from the edge of the explant, and the number of neurites passing through the line was calculated per field of observation $(550 \times 425 \mu \mathrm{m})$.

\section{Probe synthesis and in situ hybridization}

Probes were synthesized with PCR using the following primers: $\alpha 9$ integrin, 5'-AGCCGGACGCCAGAGTCCCCT-3' (forward) and 5'-GGAGGGGAT GATGTAGCAGAA-3' (reverse); and kindlin1, 5'-ATGTTCCAGCCT GATCTTTG-3' (forward) and 5'-TGCGAGTTTAGGGATGTCAG-3' (reverse). The purified PCR products were then labeled with digoxigenin (Roche) for in situ hybridization on PFA-fixed DRG sections. The procedure for in situ hybridization was performed as previously described (Carulli et al., 2006).

\section{Generation of adeno-associated virus}

The plasmids adeno-associated virus (AAV)-CMV-farnesylated GFP (fGFP), AAV-CAG- $\alpha 9-\mathrm{V} 5$, and AAV-CMV-kindlin1-GFP were amplified and sequenced before proceeding to be packaged into AAV serotype 5 (AAV5) as described previously (Hermens et al., 1999). For virus production, HEK293T cells were transfected with the individual expression and helper plasmids and kept for $3 \mathrm{~d}$ in culture. The transfected cells were then lysed by using three freeze-thaw cycles. After centrifugation, the crude lysate was subjected to iodixanol gradient $(15,25,40$, and $60 \%)$ ultracentrifugation using a Type $70 \mathrm{Ti}$ rotor (Beckman) at $490,000 \times g$ at $16^{\circ} \mathrm{C}$ for $70 \mathrm{~min}$. The virus was then collected and concentrated using an Amicon Ultra-15 device (Millipore). The titer of the virus was then determined by using real-time quantitative PCR: $1.52 \times 10^{13} \mathrm{GC} / \mathrm{ml}$ for AAV5-fGFP, $1.54 \times 10^{13} \mathrm{GC} / \mathrm{ml}$ for AAV5- $\alpha 9$-V5 , and $1.41 \times 10^{13} \mathrm{GC} / \mathrm{ml}$ for AAV5-kindlin1-GFP.

\section{Animal surgeries}

All animal surgeries were conducted in accordance with the United Kingdom Animals (Scientific Procedures) Act 1986. Adult 2-month-old male Lewis rats were used for surgery. Each animal was allocated a number and assigned into one of the control or experimental groups randomly. The experimenter was blinded throughout the entire study, including during behavioral testing and axon quantification. During surgery, the animals were anesthetized in $2-4 \%$ isoflurane, in $1.5-2.0 \mathrm{~L} / \mathrm{min}$ oxygen. A left hemilaminectomy was performed at the level C5-T1. One microliter of the virus at a working titer of $2 \times 10^{12} \mathrm{GC} / \mathrm{ml}$ was injected into the left $\mathrm{C} 6$ and C7 DRG using a 33 gauge needle syringe (Hamilton) with an infusion syringe pump (World Precision Instruments) at $0.1 \mu \mathrm{l} / \mathrm{min}$, with additional 3 min before needle withdrawal. At the same time, a concurrent dorsal root crush injury (left C5-C8) was performed with a pair of fine Bonn forceps (Fine Science Tools) for $3 \times 10 \mathrm{~s}$ for each root. A week before the final experimental time point, a total of $5 \mu \mathrm{l}$ of $1 \%$ cholera toxin B subunit (CTB; List Biological Labs) was injected into the left footpad and the four digits (Carulli et al., 2010). At the end of the experimental time point, the animals were perfused transcardially with $4 \%$ PFA. We did not have to humanely kill any animals based on welfare reasons in this study.

\section{Sensory behavioral testing}

Ladder-rung walking task, mechanical pressure (Randall-Selitto touch sensitivity) test, and thermal pain (Hargreave's hotplate) test were administered once before the surgery and once each week after surgery for 12 weeks.

Ladder-rung walking task. Animals were placed on a 1.2-m-long horizontal ladder, with unevenly spaced rungs that were $3.0-5.0 \mathrm{~cm}$ apart. 

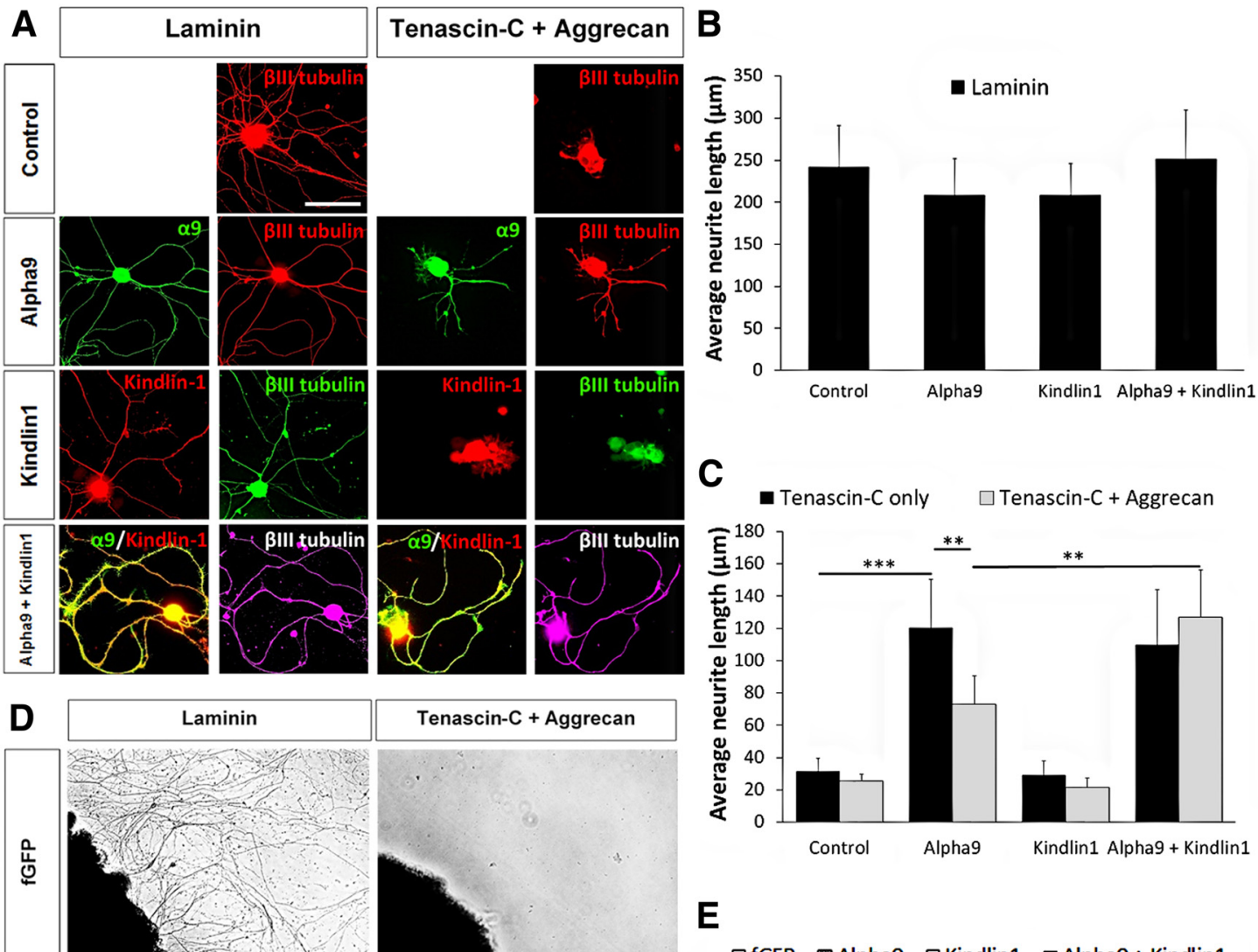

\section{E}
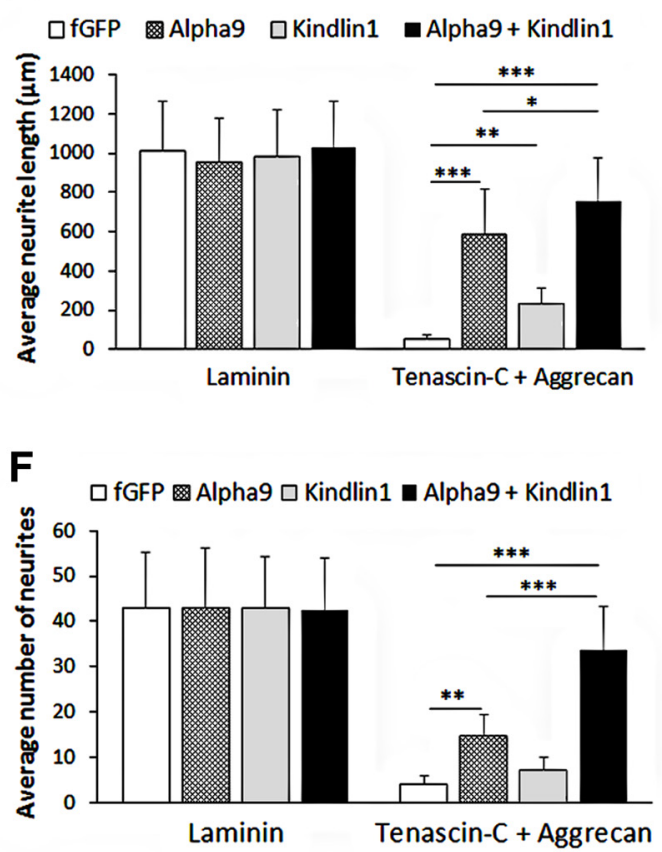

Figure 1. Coexpression of $\alpha 9$ integrin and kindlin-1 promotes DRG neurite outgrowth in vitro on tenascin- $C+$ aggrecan. $A$, Neurite outgrowth of dissociated DRG neurons, mock transfected (control) or transfected with $\alpha$-eYFP and/or kindlin1-mCherry cultured on laminin or tenascin-C + aggrecan. Scale bar, $100 \mu \mathrm{m}$. B, C, The average neurite length of dissociated DRG neurons cultured on laminin $(\boldsymbol{B})$, tenascin-C only, or tenascin- $\boldsymbol{C}+$ aggrecan $(\boldsymbol{C})$ for $3 \mathrm{~d}, n=5$. D, Neurite outgrowth of DRG explants injected with AAV5-fGFP, AAV5- $\alpha 9-V 5$, and/or AAV5kindlin1-GFP cultured on laminin or tenascin- $\boldsymbol{C}+$ aggrecan. Scale bar, $100 \mu \mathrm{m} . \boldsymbol{E}, \boldsymbol{F}$, The average neurite length $(\boldsymbol{E})$ and the average number of neurites per field of observation $(\boldsymbol{F})$ of virus-injected DRG explants cultured on laminin or tenascin- $\boldsymbol{C}+$ aggrecan for $5 \mathrm{~d}, n=5$. Results were analyzed by one-way $(\boldsymbol{B}, \boldsymbol{E}, \boldsymbol{F})$ or two-way $(\boldsymbol{C})$ ANOVA and expressed as mean \pm SEM. ${ }^{*} p<0.05,{ }^{* *} p<$ 0.01 , and ${ }^{* * *} p<0.001$ were statistically significant.

Sugar pellets were provided at the end of the ladder. The animals were allowed to walk on the ladder for three trials and video recorded. The average number of slips from the three trials was quantified.

Mechanical pressure test. Animals were placed in an enclosure with a metal mesh bottom. A probe connected to an electronic anesthesiometer
(IITC Life Science) was applied with a gradual increase of pressure to the footpad of the forepaw, until the animal withdrew its paw. The maximum pressure recorded was termed as the withdrawal force (in grams). Five trials were performed on each forepaw, left (experimental) and right (internal control). The trial was terminated if the animal failed to re- 
spond within $100 \mathrm{~g}$. The average withdrawal force was determined after eliminating the highest and lowest measurements.

Thermal test. Animals were placed in an enclosure with a fiberglass bottom. An infraredemitting device (Ugo Basile) was placed directly under the footpad of the forepaw, until the animal withdrew its paw. The infrared intensity was set at 48 units. The time between the onset of the heat stimulus and withdrawal of the paw was termed as the withdrawal latency (in seconds). Three trials were performed on each forepaw, left (experimental) and right (internal control). The trial was terminated if the animal failed to respond within $20 \mathrm{~s}$. The average withdrawal latency was calculated by averaging the three trials.

\section{Electrophysiology}

Animals were terminally anesthetized with urethane (Sigma) at a dosage of $1.5 \mathrm{~g} / \mathrm{kg}$. A laminectomy was performed at the level $\mathrm{C} 4-$ T2. The left dorsal roots C4, C5, C8, and T1 were cut acutely before the recording. The incision cavity was filled with paraffin oil (Sigma). The stimulating electrodes were inserted in parallel into the footpad of the left forepaw (experimental) or right forepaw (internal control). The recording microelectrodes ( platinum/20\% iridium metal; Harvard Apparatus) were inserted into the left and right dorsal horns $(\sim 1 \mathrm{~mm}$ depth$)$, perpendicularly to the spinal cord. The parameters for electrical stimulation were $4 \mathrm{~mA}, 100$ $\mu \mathrm{s}$, and $5 \mathrm{~Hz}$. The readings were recorded using Spike2 (Cambridge Electronic Design).

\section{Immunostaining}

Sections of PFA-fixed tissues were cut at $14 \mu \mathrm{m}$ on a cryostat. Sections were blocked in $0.4 \%$ Triton X-100 (Sigma) and 10\% normal goat serum (Invitrogen). The tissues were then incubated with primary antibodies overnight at $4^{\circ} \mathrm{C}$ and secondary antibodies for $2 \mathrm{~h}$ at room temperature. After that, the tissues were washed in triplicate of $0.2 \%$ Triton X-100 in PBS and then mounted with Fluorosave (Calbiochem). Primary antibodies used were rabbit anti- $\beta 1$-integrin (1:500; Millipore), chicken anti$\beta$ III-tubulin (1:500; Abcam), mouse anti- $\beta$ III-tubulin (1:500; Sigma), mouse anti-focal adhesion kinase (FAK; 1:500; Invitrogen), rabbit antipY397FAK (1:250; Invitrogen), chicken anti-GFP (1:500; Invitrogen), rabbit anti-GFP (1:1000; Invitrogen), mouse anti-mCherry (1:250; Clontech), mouse anti-V5 (1:250; Invitrogen), mouse anti-chondroitin sulfate (1:400; Sigma), rabbit anti-laminin (1:500; Sigma), rabbit antitenascin-C (1:250; Abcam), mouse anti-neurofilament (NF) 160/200 (1: 500; Sigma), mouse anti-NF200 (1:500; Sigma), rabbit anti-calcitonin gene-related peptide (CGRP; 1:1000; Sigma), biotinylated isolectin B4 (IB4; 1:500; Vector Laboratories), goat anti-CTB (1:500; List Biological Labs), and guinea pig anti-VGluT2 (1:500; Synaptic Systems). Secondary antibodies used were Alexa Fluor 488, 568, 647, or 660 (1:500; Invitrogen).

\section{Microscopy and statistical analysis}

Fluorescence imaging was performed using a Leica DM6000 epifluorescent microscope and a Leica DMI4000B confocal microscope. Images were analyzed using NIH ImageJ. Bar graphs were shown with mean \pm SEM produced using Microsoft Excel 2013. Statistical analysis was performed using SPSS version 22, and statistical differences between groups were determined by using Student's $t$ test, one-way, two-way, or repeated-measures ANOVA with Bonferroni's post hoc test when appropriate. For all statistical analyses, a $p$ value of 0.05 was considered to be significant.

\section{Results}

Expression of both $\alpha 9$ integrin and kindlin-1 promotes DRG neurite outgrowth on tenascin- $\mathrm{C}$ and aggrecan

To study the independent and synergistic effects of $\alpha 9$ integrin and kindlin-1 in vitro, dissociated and explant adult DRG cultures were used to assess neurite outgrowth. Dissociated DRG neurons were transfected with the fusion constructs $\alpha 9$-eYFP and/or kindlin1-mCherry, alongside mock-transfected controls. Transfected DRG neurons were cultured on a substrate of laminin $(10 \mu \mathrm{g} / \mathrm{ml})$ alone or tenascin-C $(10 \mu \mathrm{g} / \mathrm{ml})$ with or without aggrecan $(10 \mu \mathrm{g} / \mathrm{ml})$ for $3 \mathrm{~d}$ (Fig. $1 A-C)$. Because of a lack of commercially reliable antibodies for $\alpha 9$ integrin and kindlin-1, the immunostaining of eYFP was used for detecting $\alpha 9$ integrin and mCherry for kindlin-1. In all cases, $\beta$ III-tubulin staining was used for neurite length analysis, but $\alpha 9$ integrin and kindlin-1 colocalized with $\beta$ III-tubulin being present throughout the axons (Fig. 1A). On laminin, the average neurite length was $\sim 210$ $\mu \mathrm{m}$ for all groups with no statistical differences (Fig. 1B). On tenascin substrates, there was almost no growth except from neurons transfected with $\alpha 9$ integrin: the $\alpha 9$-only $(121 \pm 30 \mu \mathrm{m})$ and $\alpha 9+$ kindlin1 $(110 \pm 34 \mu \mathrm{m})$ groups had significantly greater neurite outgrowth $\left(^{* * *} p=1.01 \mathrm{e}^{-5}\right.$, two-way ANOVA, $n=5$ repeats of 20 neurons each) compared with the control $(32 \pm 8 \mu \mathrm{m})$ and kindlin1-only $(29 \pm 9 \mu \mathrm{m})$ groups (Fig. $1 C)$. On tenascin-C + aggrecan, the $\alpha 9$-only group showed a significant inhibition of neurite outgrowth by aggrecan $(73 \pm 18 \mu \mathrm{m}$; ${ }^{* *} p=0.00274$, two-way ANOVA, $\left.n=5\right)$. The $\alpha 9+$ kindlin 1 group extended long neurites on tenascin-C + aggrecan (126 \pm $30 \mu \mathrm{m}$ ), reversing the inhibitory effect of aggrecan.

To further study the synergistic effect of $\alpha 9$ integrin and kindlin-1, we used DRG explant cultures. Specifically, the left C5-C7 DRGs were injected in vivo with the viruses AAV5-fGFP, AAV5- $\alpha$-V5, and/or AAV5-kindlin1-GFP 4 weeks before being harvested for explant culture. The DRG explants were cul- 

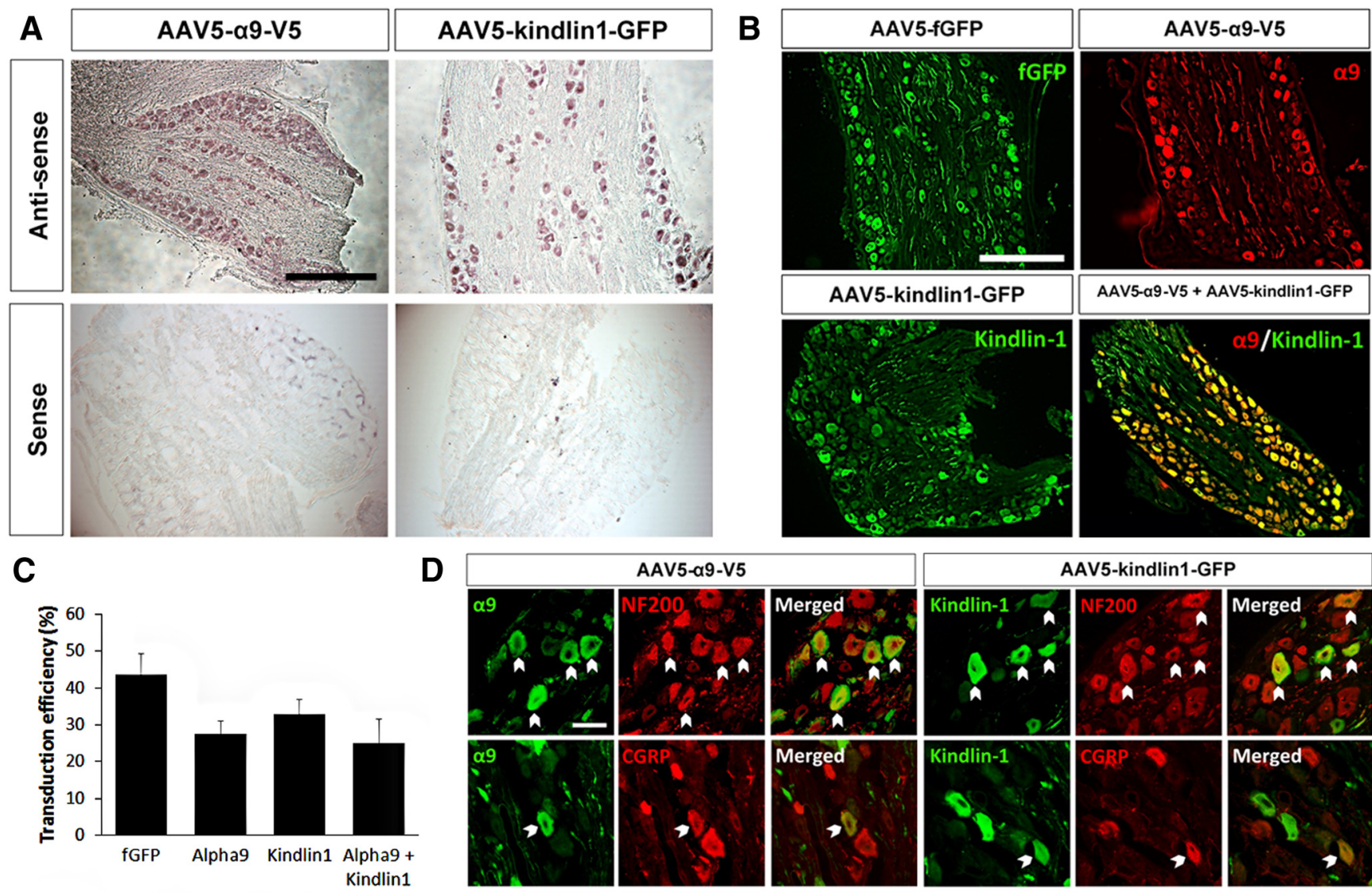

Figure 3. Expression of $\alpha 9$ integrin and kindlin-1 in DRG neurons 4 weeks after direct injection. $A$, In situ hybridization of AAV5- $\alpha 9-V 5$ or AAV5-kindlin1-GFP injected DRG sections, labeled with antisense and sense probes for $\alpha 9$ integrin or kindlin-1. Scale bar, $500 \mu \mathrm{m}$. B, DRG sections injected with AAV5-fGFP, AAV5- $\alpha 9-V 5$ and/or AAV5-kindlin1-GFP. Scale bar, 500 $\mu \mathrm{m}$. C, Transduction efficiencies of AAV5-fGFP, AAV5- $\alpha 9-V 5$, and AAV5- kindlin1-GFP in DRG neurons, expressed as mean \pm SEM, $n=5$. D, DRG sections injected with AAV5- $\alpha 9-$ V5 or AAV5kindlin1-GFP, colabeled with antibodies to NF200 or CGRP. Scale bar, $50 \mu \mathrm{m}$.

tured on a substrate of laminin or tenascin-C + aggrecan for $5 \mathrm{~d}$ (Fig. $1 D-F$ ). On laminin, the average neurite length was $\sim 1000$ $\mu \mathrm{m}$ for all groups (Fig. $1 E$ ), with an average of 43 neurites per field of observation (Fig. $1 F$ ). On tenascin-C + aggrecan, the $\alpha 9$ and $\alpha 9+$ kindlin 1 groups extended significantly longer neurites ${ }^{* \star *} p=1.76 \mathrm{e}^{-13}$, one-way ANOVA, $\left.n=5\right)$ than the fGFP control group (Fig. 1E). The $\alpha 9+$ kindlin 1 group had the longest average neurite outgrowth (757 $\pm 221 \mu \mathrm{m})$, followed by $\alpha 9$-only $(584 \pm 233 \mu \mathrm{m})$, kindlin 1-only $(224 \pm 82 \mu \mathrm{m})$, and fGFP (55 \pm $21 \mu \mathrm{m})$. For the number of neurites per field of observation, the $\alpha 9+$ kindlin1 group had $34 \pm 10$ neurites $\left({ }^{* *} p=\right.$ $4.77 \mathrm{e}^{-7}$, one-way ANOVA, $n=5$ ), and the $\alpha 9$-only group had $15 \pm 5$ neurites $\left({ }^{* *} p=0.00364\right.$, one-way ANOVA, $n=5$ ) compared with $<10$ neurites in the kindlin1-only and fGFP groups (Fig. $1 F$ ).

Additionally, the overexpression of kindlin-1 increased the phosphorylation of FAK $\left({ }^{*} p=0.0108\right.$, one-way ANOVA, $\left.n=5\right)$, demonstrated by an increased immunoreactivity to pY397 FAK in the kindlin1-only (1.2 \pm 0.4 unit) and $\alpha 9+$ kindlin1 $(1.3 \pm$ 0.1 unit) groups (Fig. $2 A, B$ ), indicating downstream signaling cascades triggered by integrin activation (Tan et al., 2011). Collectively, these experiments showed that, in both dissociated and explant cultures, $\alpha 9$ integrin expression allowed neurite growth on tenascin-C, but this was inhibited by the presence of aggrecan, confirming our previous results. However, additional expression of kindlin-1 with $\alpha 9$ integrin allowed the neurites to overcome the inhibitory effect of CSPG (aggrecan).
Expression of $\alpha 9$ integrin and kindlin1 in vivo by AAV

Previous studies have shown that adult rat DRG neurons do not express $\alpha 9$ integrin or kindlin1 (Andrews et al., 2009; Tan et al., 2012; Chiu et al., 2014). To express $\alpha 9$ integrin and kindlin1 ectopically in vivo in DRG neurons, we used AAV5 to package the fusion constructs AAV-CMV-fGFP, AAV-CAG- $\alpha 9-\mathrm{V} 5$, and AAV-CMV-kindlin1-GFP. Compared with lentivirus and other AAV serotypes $(1,2,3,4,6$, and 8), AAV5 has the highest efficiency in transducing DRG neurons over a long time course, up to 12 weeks, when injected directly into the DRG (Mason et al., 2010).

First, we confirmed that our AAVs will cotransduce sensory neurons. Four weeks after direct injection of AAV $5-\alpha 9-\mathrm{V} 5$ and AAV5-kindlin1-GFP into C6-C7 DRGs, in situ hybridization confirmed the positive expression of $\alpha 9$ integrin and kindlin 1 mRNAs, respectively (Fig. $3 A$ ). Immunostaining analysis of virus-injected DRG sections showed that AAV5-fGFP had a transduction efficiency of $44 \pm 6 \%$, whereas AAV5- $\alpha 9-$ V 5 had a transduction efficiency of $28 \pm 3 \%$, with $33 \pm 4 \%$ for AAV5kindlin1-GFP and $25 \pm 6 \%$ for the cotransduction of AAV5$\alpha 9-V 5+$ AAV5-kindlin1-GFP (Fig. 3B,C). Transduction efficiencies were obtained by measuring the ratio of GFP and/or V5-positive cell bodies with $\beta$ III-tubulin-positive cell bodies. Furthermore, additional immunostaining showed that AAV5$\alpha 9-\mathrm{V} 5$ and AAV5-kindlin1-GFP transduced both largediameter NF200-positive and small-diameter CGRP-positive DRG neurons (Fig. 3D). Within the DRG and dorsal root, many 
axons containing both $\alpha 9$ integrin and kindlin1, visualized by V5 and GFP staining, respectively, were seen, and bright kindlin1-GFP-containing axons were clearly seen passing up the spinal cord and innervating the cuneate nucleus, validating it as a good axon tracer equivalent to GFP alone. The staining of $\alpha 9-\mathrm{V} 5$ was dimmer because of the limitations of the antibody recognizing the short V 5 tag, but in most cases, axons were seen in the dorsal column up to the top of the spinal cord.

Expression of both $\alpha 9$ integrin and kindlin-1 promotes sensory axon regeneration in vivo in a timedependent manner

AAV5- $\alpha$ 9-V5, AAV5-kindlin1-GFP, or a combination of the two or AAV5-fGFP control was injected into the left C6 and C7 DRGs at the same time as a concurrent quadruple left C5-C8 dorsal root crush injury in adult rats (four groups of $\mathrm{n}=$ 10). Lesions of these four dorsal roots have been demonstrated to be a useful model for forepaw deafferentation (Wu et al., 2009). Twelve weeks after virus injection and injury, axon quantification was performed on the C7 segment of the spinal cord, corresponding to the C7 dermatome map and the area of the forepaw for behavioral testing and electrophysiology (Takahashi and Nakajima, 1996). Depending on which AAV5 the animal had been injected with, the immunostaining of fGFP, the V5 tag on $\alpha 9$, and/or the GFP tag on kindlin-1 was used as a neuronal tracer for axon quantification. In addition, in all animals, CTB was injected into the left forepaw as an additional neuronal tracer to ensure that regeneration measures were not confused by the use of different labels and to confirm for the completeness of dorsal root axotomy through staining of terminals in the cuneate nucleus.

\section{Completeness of dorsal root axotomy}

To verify the completeness of axotomy in our crush injury model, we examined the degree of denervation in the spinal cord using electrophysiology and anatomy. One week after dorsal root crush injury, electrophysiological recordings from the dorsal horn in a group of five animals showed no compound action potential, and no additional change was observed when the root was cut subsequently (Fig. 4A). In the main experiment, we used connection to the cuneate nucleus as an indicator of incomplete lesioning. In addition to kindlin-1, which can be observed filling axons and terminals in the cuneate nucleus of animals with no dorsal root injury, we also used CTB for transganglionic tracing of the dorsal column axons (Fig. 4B). This allowed us to further verify the completeness of our crush injury by excluding animals that showed visible CTB and/or kindlin-1 staining in the cuneate nucleus from all anatomical, behavioral, and electrophysiological analyses. Using this criteria, from a total of 58 animals that underwent surgery, we excluded three animals that showed evidence of incomplete crush injury in the cuneate nucleus.
Regeneration in the dorsal root, dorsal root entry zone, and C7 spinal cord segment

To assess ingrowth into the cord from the virus-injected C7 DRG, we analyzed axon regeneration in the dorsal root, dorsal root entry zone (DREZ), and C7 spinal cord (Fig. 5A). Within the dorsal root, all groups had $\sim 47$ regenerated axons per 14 $\mu \mathrm{m}$ section (three sections per animal, $n=10$ ) distal to the crush site with no significant difference found between groups (Fig. 5B). Within the DREZ, all three experimental groups, $\alpha 9$-only (12 \pm 3 axons), kindlin 1 -only ( $15 \pm 4$ axons), and $\alpha 9$ + kindlin 1 (13 \pm 3 axons), showed significantly more axons per $14 \mu \mathrm{m}$ section (three sections per animal, ${ }^{\star} p=0.0466$, one-way ANOVA, $n=10)$ than the fGFP control group $(2 \pm 1$ axons; Fig. 5C). In the $\mathrm{C} 7$ spinal cord segment, both the kindlin1-only (22 \pm 5 axons) and $\alpha 9+$ kindlin $1(48 \pm 10$ axons) groups had significantly more axons per section (three sections per animal, ${ }^{\star * *} p=7.99 \mathrm{e}^{-4}$, one-way ANOVA, $n=$ $10)$ than the fGFP control $(0.3 \pm 0.2$ axons $)$ and $\alpha 9$-only $(2 \pm$ 0.5 axons) groups (Fig. 5D). Furthermore, the $\alpha 9+$ kindlin 1 group had significantly more axons per section $\left({ }^{\star} p=0.0361\right.$, one-way ANOVA, $n=10$ ) than the kindlin 1-only group. Axons expressing both $\alpha 9$ integrin and kindlin-1 were observed in the spinal cord, especially in the cuneate fasciculus and dorsal horn (Fig. $5 E, G$ ). For the fGFP control group, no axons were observed growing into the DREZ and spinal cord (Fig. 5F). 

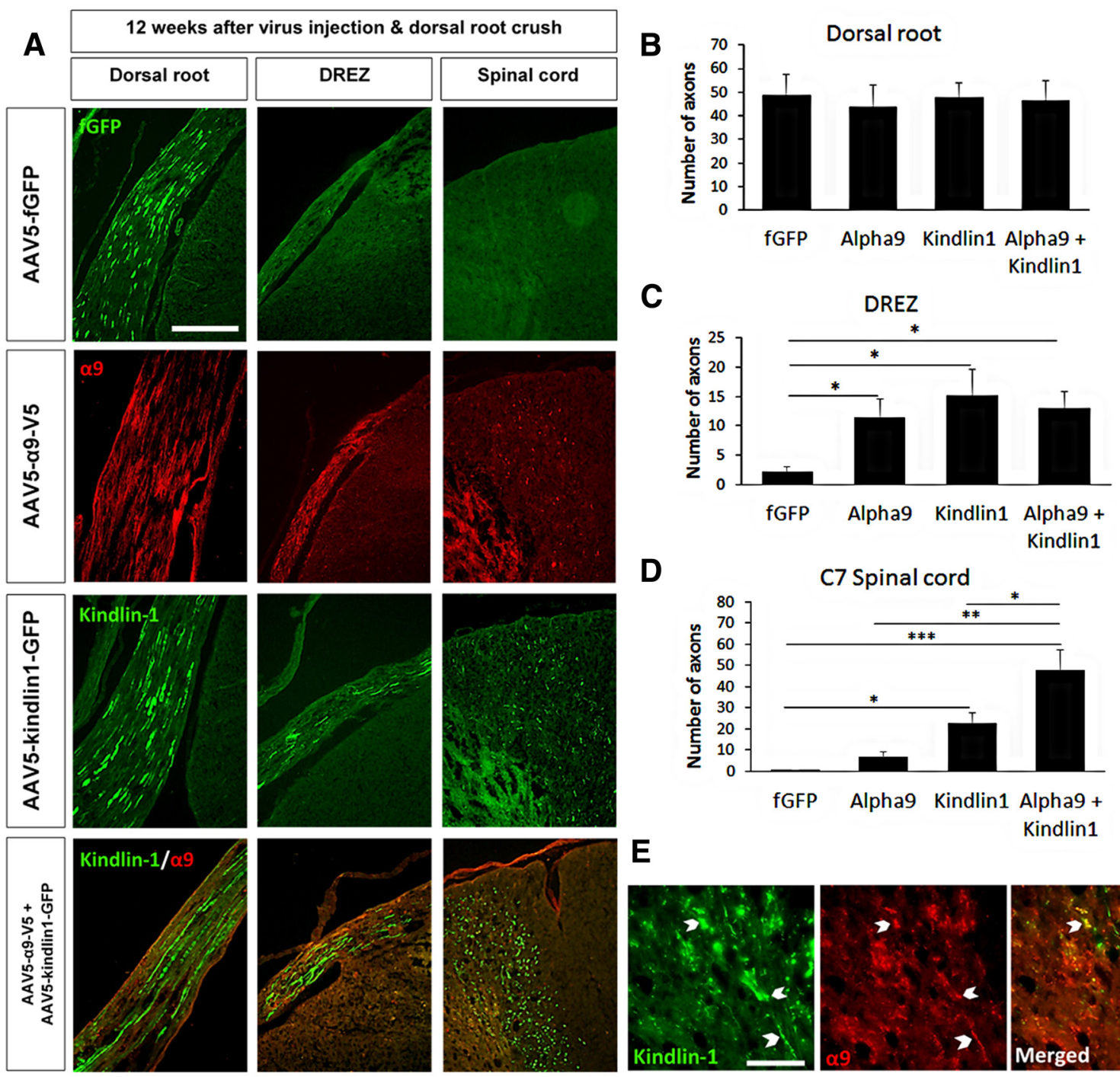

D

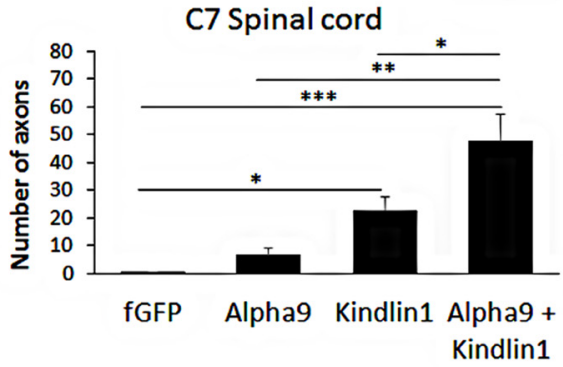

$\mathbf{F}$

AAV5-fGFP G AAV5- $\alpha 9-V 5+$ AAV5-kindlin1-GFP

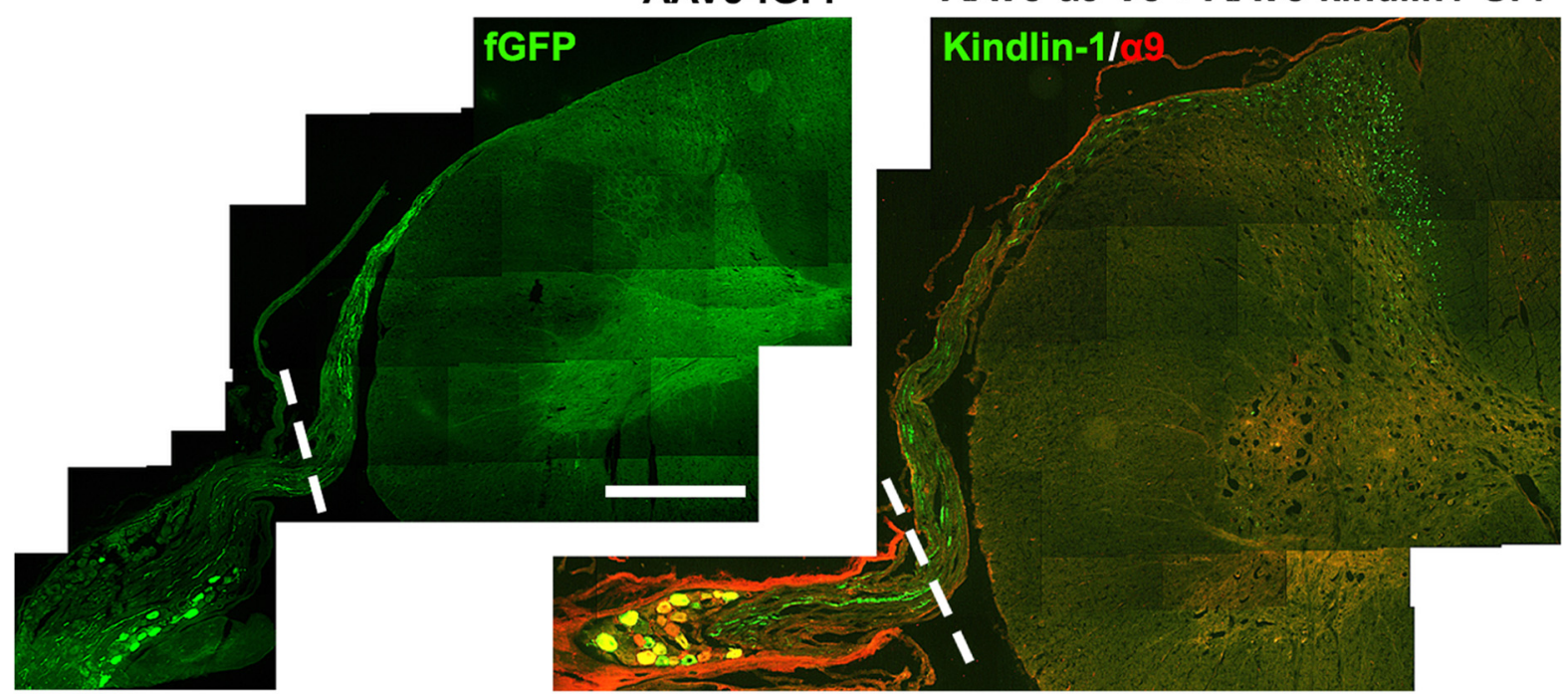

Figure 5. Coexpression of $\alpha 9$ integrin and kindlin-1 promotes sensory axon regeneration into the spinal cord at level C7. A, Dorsal root, DREZ, and spinal cord C 7 sections 12 weeks after being injected with AAV5-fGFP, AAV5- $\alpha 9-V 5$, and/or AAV5- kindlin1-GFP and followed by dorsal root crush injury. Scale bar, $250 \mu \mathrm{m} . \boldsymbol{B}, \boldsymbol{D}$, The number of axons per section in the dorsal root (B), DREZ $\left(\boldsymbol{C}\right.$, and $\mathrm{C}$ spinal cord (D) after 12 weeks of treatment, three sections per animal, analyzed by one-way ANOVA and expressed as mean \pm SEM. ${ }^{*} p<0.05,{ }^{* *} p<0.01$, and ${ }^{* * *} p<0.001$ were statistically significant, $n=10$ per group. $\boldsymbol{E}$, Axons coexpressing kindlin-1 and $\alpha 9$ integrin in the spinal cord. Scale bar, $50 \mu \mathrm{m}$. $\boldsymbol{F}, \boldsymbol{G}$, Spinal cord sections at level C7 of AAV5-fGFP $(\boldsymbol{F})$ or AAV5- $\alpha 9-V 5+$ AAV5- kindlin1-GFP (G) injected animals 12 weeks after dorsal root crush injury. The white-dotted lines represent the region of dorsal root crush. Scale bar, $650 \mu \mathrm{m}$. 


\section{A AAV5-a9-V5 + AAV5-kindlin1-GFP}

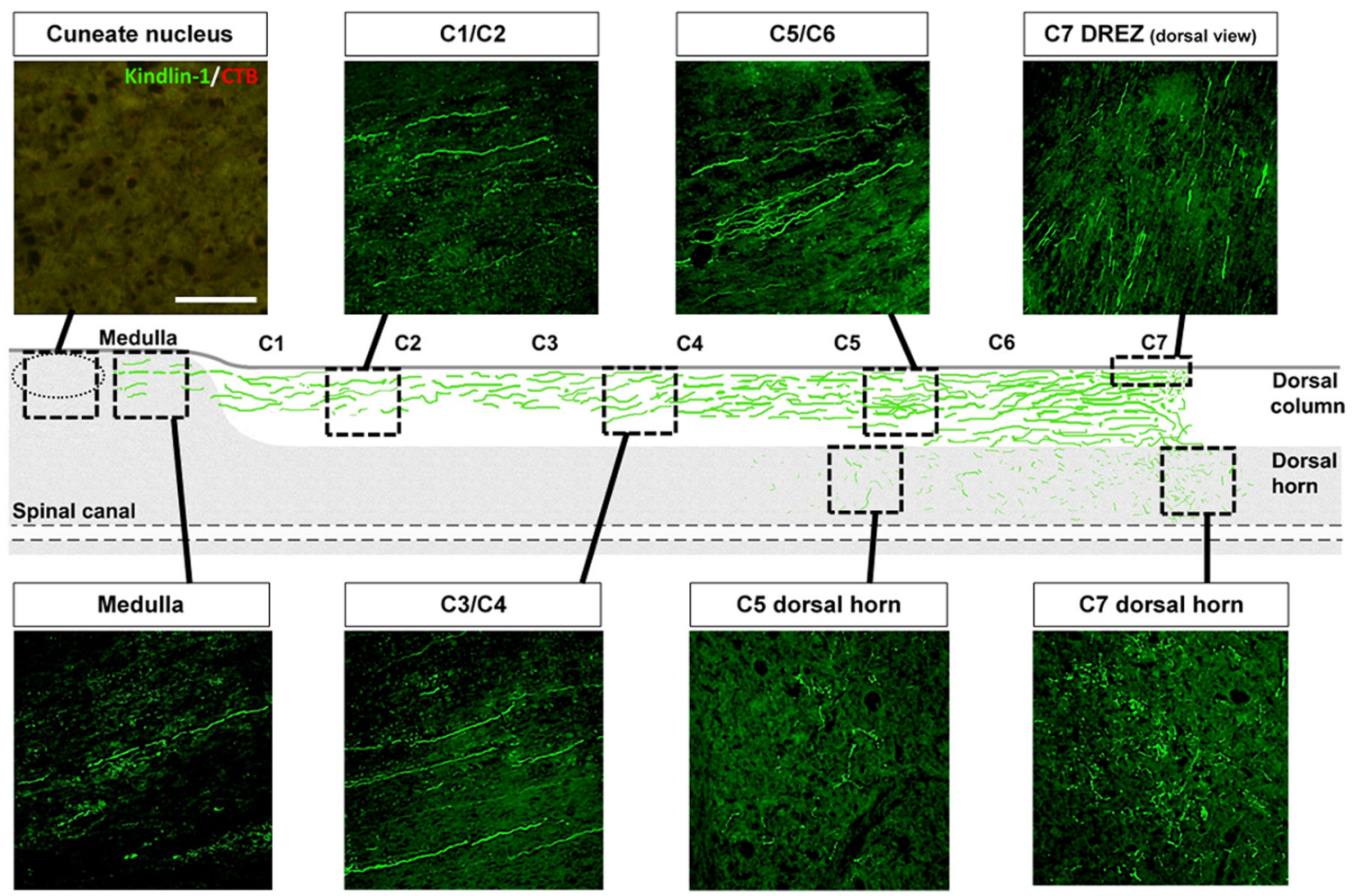

B AAV5- $99-$ V5
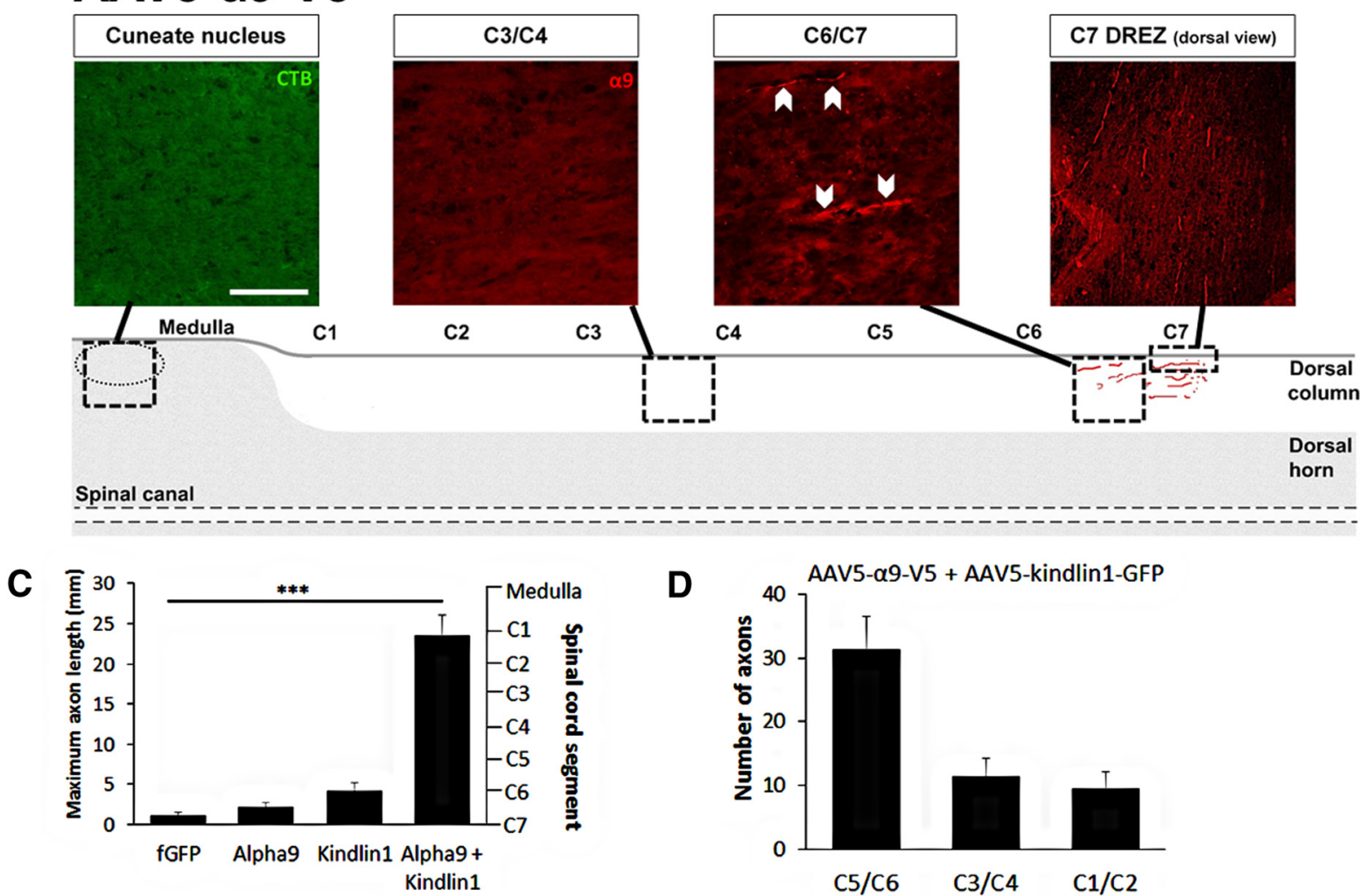

Figure 6. Coexpression of $\alpha 9$ integrin and kindlin-1 promotes sensory axon regeneration in the dorsal column up to $C 1$ level and the medulla. $\boldsymbol{A}, \boldsymbol{B}$, Diagrams representing a single $14 \mu \mathrm{m}$ parasagittal spinal cord section of AAV5- $\alpha 9-V 5+$ AAV5- kindlin1-GFP $(\boldsymbol{A})$ or AAV5- $\alpha 9-V 5(\boldsymbol{B})$ injected animals 12 weeks after dorsal root crush injury, showing regenerating axons in various regions along the spinal cord. Scale bar, $250 \mu \mathrm{m}$. The diagrams were produced by drawing the axons from single sections taken from the middle of the dorsal horn into the arrowed squares and then interpolating between them. Each dorsal column is $\sim 600 \mu \mathrm{m}$ across or $\sim 40$ parasagittal $14 \mu \mathrm{m}$ sections. $C$, The maximum length (in millimeters) of regenerating axons observed along the spinal cord for each group, analyzed by one-way ANOVA and expressed as mean \pm SEM. ${ }^{* *} p<0.001$ was statistically significant, $n=5$. D, The number of axons per section at $\mathrm{C} 5 / \mathrm{C} 6, \mathrm{C} 3 / \mathrm{C} 4$, and $\mathrm{C} 2 / \mathrm{C} 1$ spinal cord segments of the $\alpha 9+$ kindlin 1 group, expressed as mean \pm SEM, $n=5$. 

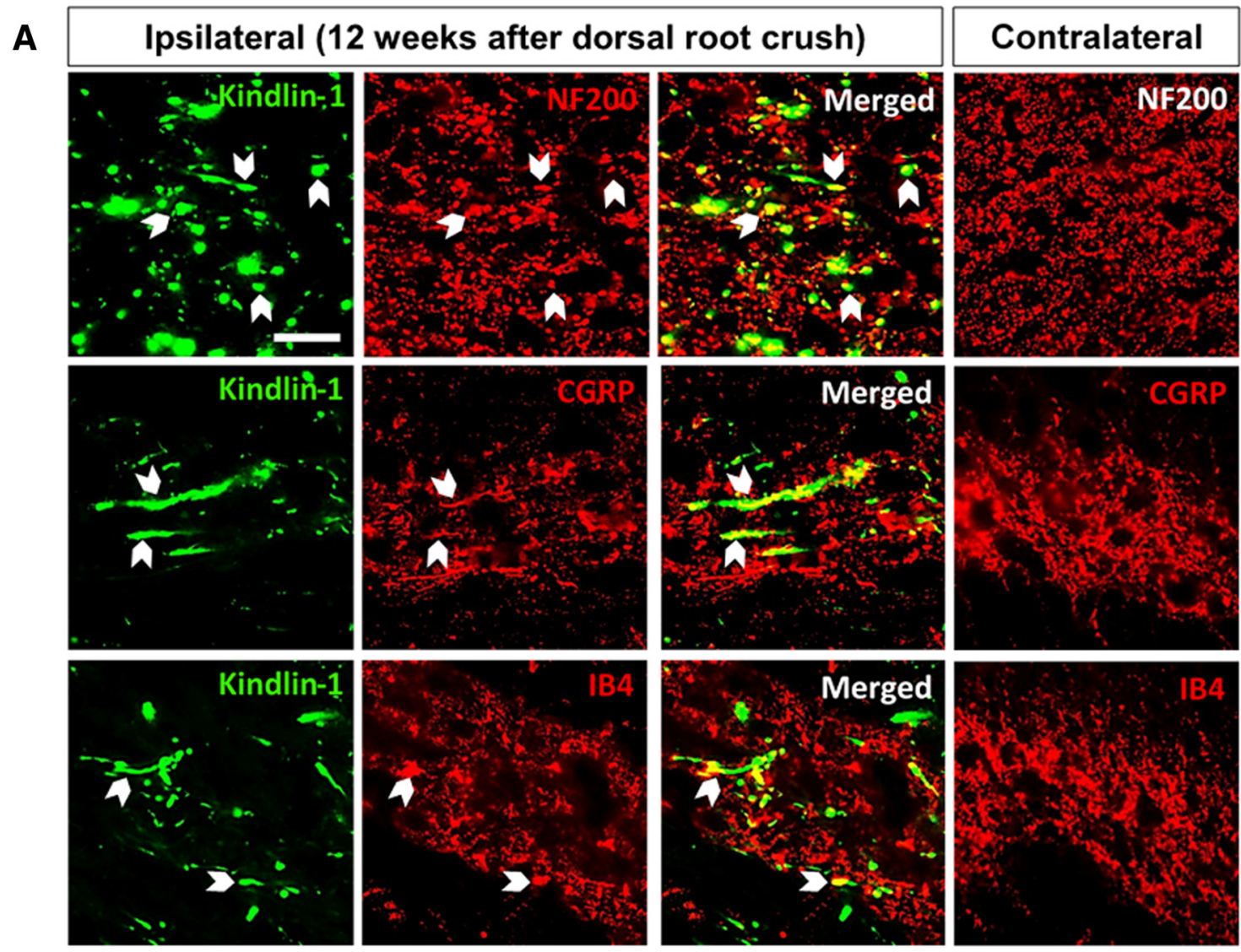

B

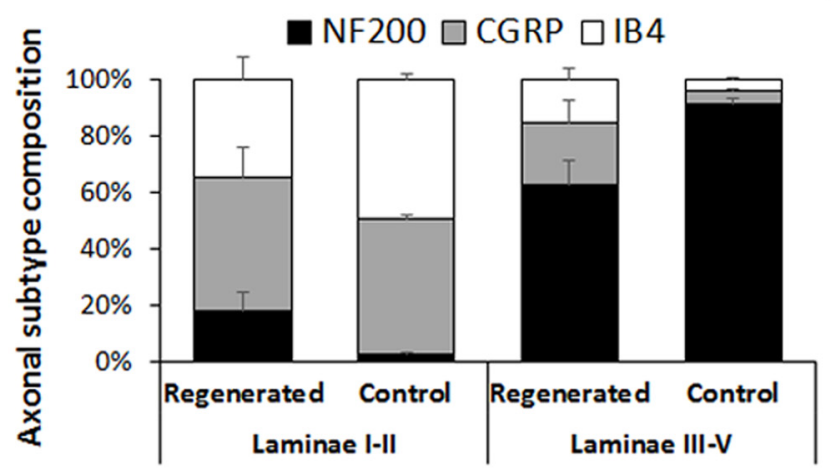

C

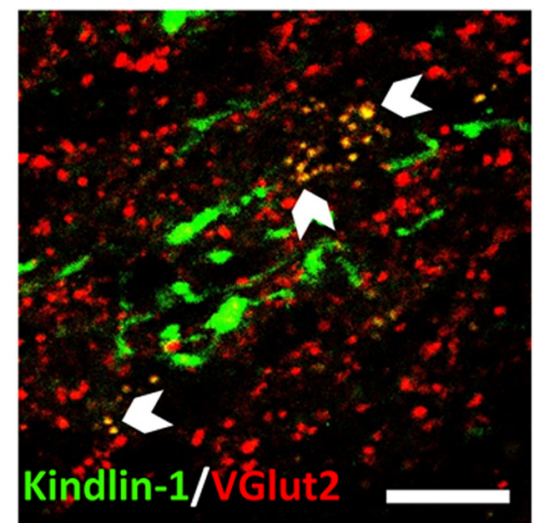

Figure 7. Coexpression of $\alpha 9$ integrin and kindlin-1 promotes axonal reconnections in the spinal cord. $A$, Ipsilateral spinal cord C7 sections showing kindlin1-positive regenerating axons that are immunopositive for NF200 in the dorsal column and CGRP and IB4 in the dorsal horn. The contralateral control side is the corresponding uninjured region of the spinal cord. Scale bar, $50 \mu \mathrm{m}$. $\boldsymbol{B}$, The composition of axonal subtypes NF200, GGR, and IB4 in laminae I-II and laminae III-V of the dorsal horn on the ipsilateral regenerated and contralateral control sides. Results expressed as mean \pm SEM, three sections per animal, $n=5$. C, Spinal cord section showing potential synaptic reconnections of kindlin1-positive axonal terminals with VGluT2-positive neurons in the dorsal horn. Scale bar, $50 \mu \mathrm{m}$.

Long-distance regeneration in the spinal cord with dual expression of $\alpha 9$ integrin and kindlin-1

For animals treated with both $\alpha 9$ integrin and kindlin-1, additional assessment along the spinal cord revealed regenerated axons in the dorsal column all the way up to level $\mathrm{Cl}$ and medulla with no kindlin1- or CTB-immunopositive axons observed in the cuneate nucleus (Fig. 6A). However, only a limited amount of regeneration with less than a spinal segment was observed in animals treated with $\alpha 9$ integrin only (Fig. 6B). The long-distance regeneration with a maximum axon length averaged between animals of $25 \pm 3 \mathrm{~mm}$ observed in the $\alpha 9+$ kindlin1 group was highly significant ${ }^{* * *} p=1.66 \mathrm{e}^{-10}$, one-way ANOVA, $\left.n=5\right)$ compared with the fGFP, $\alpha 9$-only, and kindlin1-only groups in which only one segment or less $(\leq 4 \mathrm{~mm})$ regeneration was observed (Fig. 6 C). In the $\alpha 9+$ kindlin 1 group at C5/C6 segment, an average of 31 axons per section was counted, whereas at $\mathrm{C} 3 / \mathrm{C} 4$ and $\mathrm{C} 1 / \mathrm{C} 2$ segments, there was still a robust projection with $\sim 10$ axons per section (Fig. 6D).

Additionally, further assessment of those regenerated axons revealed that a proportion of the regenerated kindlin1-positive axons were NF200, CGRP, and IB4 immunopositive (Fig. 7A). Many NF200-immunopositive axons were observed as axons of passage in the cuneate fasciculus of the dorsal column. Within the dorsal horn, we counted the proportion of kindlin1-positive re- 
generated processes that stained for the three markers. NF200 processes were $17 \pm 6 \%$ in laminae I-II (substantia gelatinosa) and $59 \pm 8 \%$ in the deeper laminae III-V (nucleus proprius) of the dorsal horn. CGRP processes were $44 \pm 10 \%$ in laminae I-II and $21 \pm 7 \%$ in laminae III-V, and IB4-immunopositive processes were $32 \pm 8 \%$ in laminae $1-$ II and $14 \pm$ $4 \%$ in laminae III-V. The innervation pattern of axonal subtypes was similar to normal spinal cord but less precise (Fig. $7 B$ ). Using confocal microscopy of single optical slices, kindlin1-expressing sensory axon terminals were observed in the dorsal horn to be colocalized with the VGluT2 puncta of dorsal horn neurons, indicating potential synaptic reconnections (Fig. 7C). Together, these data show that axons expressing both $\alpha 9$ integrin and kindlin-1 are able to regenerate through the DREZ, in which they follow appropriate pathways and terminal zones within the spinal cord, and within 12 weeks, they can grow for up to seven spinal segments and $>25 \mathrm{~mm}$ in length.

\section{Time course of regeneration}

For the $\alpha 9+$ kindlin 1 group, we further assessed axon regeneration at the 3 and 6 week time points in an additional set of animals (two groups of $n=5$; Fig. $8 A$ ). At 3 weeks (which is the time it takes for maximal AAV-driven expression to build up), regenerating axons were observed in the dorsal root $(27 \pm 5$ axons per section, three sections per animal, $n=5)$, with a few in the DREZ ( $3 \pm 1$ axons, three sections per animal, $n=5$ ), and none were found in the spinal cord (Fig. $8 B$ ). At 6 weeks, significantly more regenerating axons were observed in the DREZ $(14 \pm 3$ axons per section, three sections per animal, ${ }^{\star} p=0.0414$, Student's $t$ test, $n=5$ ) and spinal cord (25 \pm 4 axons per section, 3 sections per animal, ${ }^{\star *} p=0.00951$, Student's $t$ test, $n=5$ ). Together with the data obtained at the 12 week time point, these data demonstrate that expression of both $\alpha 9$ integrin and kindlin-1 significantly promotes sensory axon regeneration in a time-dependent manner because the level of regeneration was observed to increase over time from 3 to 6 to 12 weeks.

Changes in extracellular matrix molecules in the DREZ

For this study, the DREZ was defined as the segment in the dorsal root that was immunonegative for laminin (Fig. 9A). Laminin was highly expressed in the dorsal root but not in the DREZ central where the dorsal root joins the spinal cord. Additionally, the immunoreactivity of laminin does not change in the DREZ after injury (McPhail et al., 2007), hence the staining of laminin is a good delineator between the PNS and CNS environments of the dorsal root. Twelve weeks after dorsal root crush injury, there was an upregulation of CSPGs in the injured dorsal root and of tenascin-C in the DREZ (Fig. 9B). A dorsal root crush did not

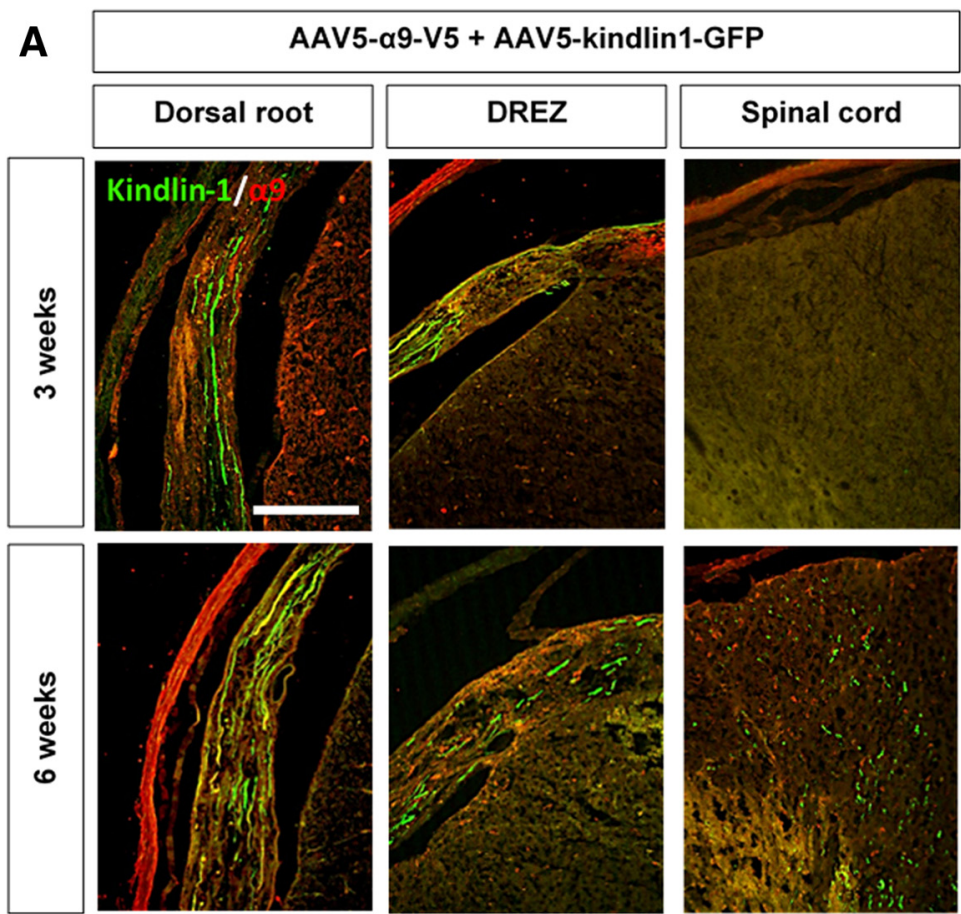

B AAV5- $\alpha 9-V 5+$ AAV5-kindlin1-GFP

\section{3 weeks $\square 6$ weeks}

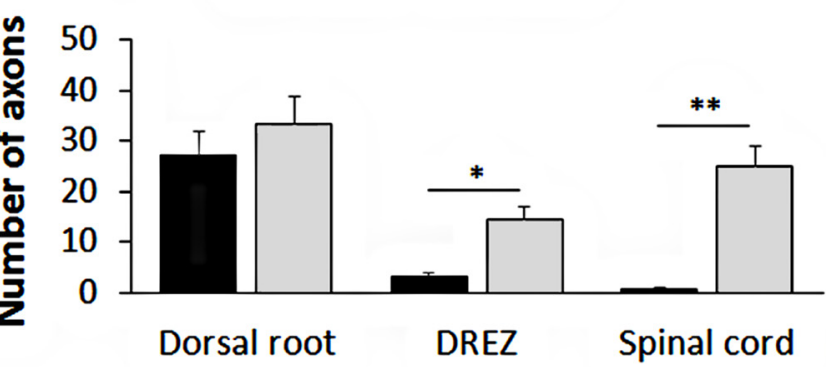

Figure 8. Coexpression of $\alpha 9$ integrin and kindlin-1 promotes sensory axon regeneration in a time-dependent manner. $\boldsymbol{A}$, Dorsal root, DREZ, and spinal cord C7 sections 3 and 6 weeks after being injected with AAV5- $\alpha 9-V 5+$ AAV5- kindlin1-GFP and 列 after 3 and 6 weeks of treatment, three sections per animal, analyzed by Student's $t$ test and expressed as mean \pm SEM. ${ }^{*} p<0.05$ and ${ }^{* *} p<0.01$ were statistically significant, $n=5$.

upregulate the expression of CSPGs and tenascin-C in the contralateral uninjured dorsal root (Fig. 9B). Axons in the fGFP control group did not grow into the tenascin-C-rich DREZ, whereas axons expressing both $\alpha 9$ integrin and kindlin- 1 were observed growing beyond the tenascin-C-rich DREZ and into the spinal cord (Fig. 9C). This is consistent with our in vitro experiments, with tenascin-C in the DREZ being inhibitory to sensory axon regeneration. However, for axons expressing $\alpha 9$ integrin, this tenascin- $\mathrm{C}$ would be a growth-promoting substrate.

\section{Treatment with $\alpha 9$ integrin and kindlin 1 promotes} electrophysiological reconnection

To further investigate functional sensory axon regeneration, electrophysiological recording was performed at the end of the 12 week experimental time point. The left dorsal roots C4, C5, C8, and $\mathrm{T} 1$ were cut acutely to eliminate spinal inputs from overlapping dermatomes but leave C7 intact. Extracellular platinumiridium recording electrodes were inserted into the left and right 
A

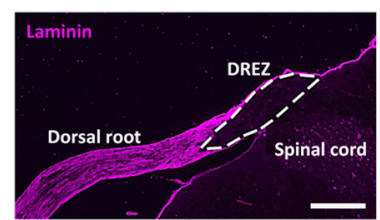

B
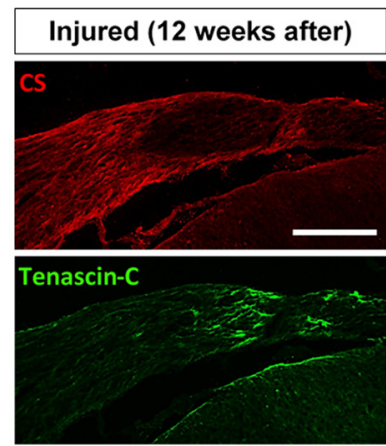

Merged
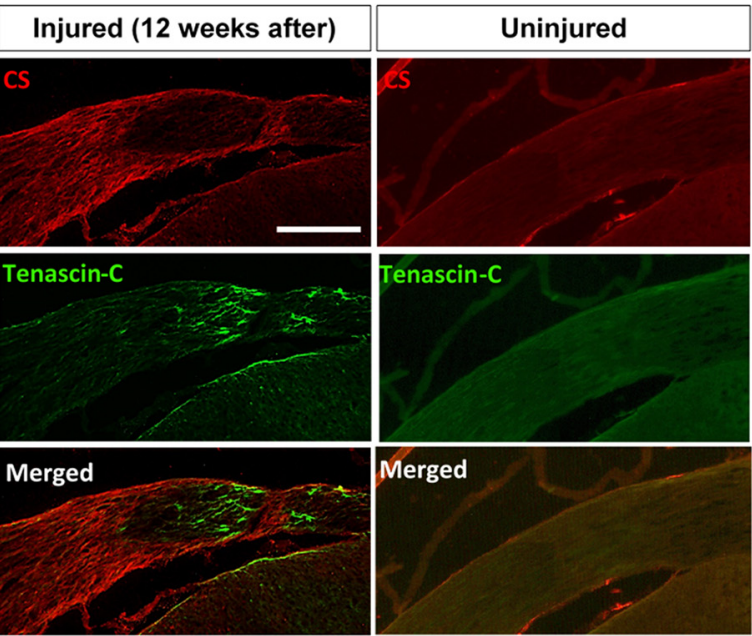

C

12 weeks after virus injection and dorsal root crush
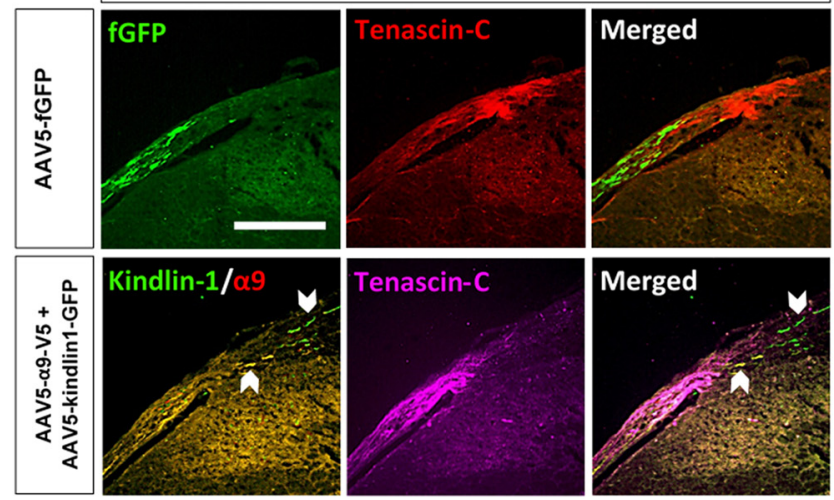

Figure 9. DREZ is a barrier for DRG axon regeneration. $\boldsymbol{A}$, The DREZ (white-bordered area) is defined as the segment in the dorsal root that is immunonegative for laminin. Scale bar, 500 $\mu \mathrm{m} . \boldsymbol{B}$, Spinal cord section labeled with antibodies to chondroitin sulfate (CS) chain and tenascin-C to show the upregulation of CSPGs in the injured dorsal root and tenascin-C in the DREZ 12 weeks after dorsal root crush injury. Scale bar, $250 \mu \mathrm{m}$. C, Spinal cord section of AAV5-fGFP or AAV5- $\alpha 9$-V5 + AAV5- kindlin1-GFP injected animals 12 weeks after dorsal root crush injury, showing that fGFP-expressing axons do not grow into the tenascin-C-rich DREZ, whereas $\alpha 9$ integrin and kindlin1-expressing axons grow beyond the tenascin-C-rich DREZ and into the spinal cord. Scale bar, $250 \mu \mathrm{m}$.

C7 dorsal horns. At the 12 week time point, there were large differences in the size of the dorsal column compound action potentials recorded from the control and three experimental groups ( $\alpha 9$-only, kindlin1-only, and $\alpha 9+$ kindlin1) (Fig. 10A). In all cases, when the $\mathrm{C} 7$ dorsal root was cut subsequently during the recording session, the compound action potential was completely eliminated. We saw no evidence of reconnection in the fGFP control group. Compared with the fGFP control group ( $3 \pm$ $0.2 \mu \mathrm{V})$, the $\alpha 9+$ kindlin 1 group showed the highest peak-topeak voltage amplitude of $64 \pm 20 \mu \mathrm{V}\left({ }^{* *} p=0.00352\right.$, one-way ANOVA, $n=5)$, followed by the $\alpha 9$-only $(21 \pm 5 \mu \mathrm{V})$ and kindlin1-only $(21 \pm 1 \mu \mathrm{V})$ groups $\left({ }^{\star} p=0.0266\right.$, one-way ANOVA, $n=5$; Fig. 10B). This was compared with an amplitude of $159 \pm 20 \mu \mathrm{V}$ in uninjured controls.
Treatment with $\alpha 9$ integrin and kindlin-1 promotes sensorymotor behavioral recovery

To examine sensory behavioral recovery, mechanical pressure (Randall-Selitto touch sensitivity) test, thermal pain (Hargreave's hotplate) test, and uneven-rung ladder-walking task were administered up to 1 week before the surgery with pretraining on the ladder and then weekly after surgery for 12 weeks. One week after surgery, the experimental left forepaw from all groups showed significant sensory deficits in all three behavioral tests compared with presurgery levels (Fig. $11 A-C$ ). This was indicated by a higher withdrawal force and a longer withdrawal time required to initiate paw withdrawal, together with an almost complete inability to place the left forepaw on the rungs during the ladder-walking task.

In the mechanical pressure test, the $\alpha 9+$ kindlin 1 group started to show a significant recovery ${ }^{* *} p=0.00926$, repeatedmeasures ANOVA, $n=10$ ) from week 8 , whereas the other three groups, fGFP control, $\alpha 9$-only, and kindlin1-only, did not show any significant recovery (Fig. 11A). In the thermal test, all three experimental groups ( $\alpha 9$-only, kindlin1-only, and $\alpha 9+$ kindlin1) showed a significant recovery $\left({ }^{*} p=0.0271\right.$, repeatedmeasures ANOVA, $n=10$ per group) compared with the fGFP control group (Fig. 11B). The $\alpha 9+$ kindlin 1 group showed a faster and more significant recovery at an earlier time point (week 5 ) compared with the kindlin1-only (week 7) and $\alpha 9$-only (week 8 ) groups. In the ladder-walking task, the control group showed very inaccurate limb placement throughout. The $\alpha 9+$ kindlin 1 group showed significant recovery in limb proprioception ${ }^{* *} p=$ 0.00631 , repeated-measures ANOVA, $n=10$ ) from week 9 , and the kindlin1-only group possibly showed marginal recovery from week $11\left({ }^{*} p=0.0429\right.$, repeated-measures ANOVA, $\left.n=10\right)$, but the fGFP control and $\alpha 9$-only groups did not recover (Fig. 11C). Together, these results indicate that the $\alpha 9+$ kindlin 1 group showed excellent sensory recovery in the mechanical pressure and thermal tests and excellent sensory-motor recovery in the ladder-walking task. The kindlin1-only group showed a delayed recovery in the thermal and possibly ladder-walking tests, whereas the $\alpha 9$-only group showed recovery only in the thermal test and the fGFP control group showed no recovery in any test.

\section{Discussion}

This study demonstrates that sensory axons are able to regenerate for substantial distances after a dorsal root axotomy provided that they have on their surface an integrin coexpressed with an inside-out activator, kindlin-1. $\alpha 9$ integrin binds to tenascin-C, a constituent of the nonpermissive environment in the adult spinal cord, and kindlin-1 prevents it from being deactivated by CSPGs. Our previous studies (Andrews et al., 2009, Tan et al., 2012) showed that expression of either $\alpha 9$ integrin or kindlin-1 in DRG neurons could enhance regeneration of axons into the spinal cord through the DREZ, but there was little growth from this point of entry along the length of the cord. In this study, we show that the combinatorial expression of $\alpha 9$ integrin and kindlin-1 promotes axon regeneration over remarkably long distances, $25 \mathrm{~mm}$ or seven spinal levels and more, all the way up to the medulla. The regenerating axons follow a relatively normal pathway, re-form synaptic connections in appropriate regions of the dorsal horn, and can re-establish sensory and sensory-motor behaviors. Although the combination of $\alpha 9$ integrin and kindlin-1 enabled useful reconstruction of sensory connections and function, our results with $\alpha 9$ integrin alone or kindlin-1 alone confirm our previous studies, promoting regeneration for $4 \mathrm{~mm}$ or less with only recovery of heat sensation. 
Expression and activation of an appropriate integrin

Axons will not grow unless they have on their surface a receptor that recognizes a ligand in their environment. Our previous work has identified $\alpha 9$ integrin as such a receptor, recognizing tenascin- $\mathrm{C}$, which is present in the DREZ and CNS environment. However, axon regeneration in vivo after expression of this integrin was modest (Andrews et al., 2009). The probable reason for the limited effect of $\alpha 9$ integrin in vivo is that it is inactivated by CSPGs and Nogo-A found in the injured CNS ( $\mathrm{Hu}$ and Strittmatter, 2008; Tan et al., 2012). The signaling pathway is not identified, but intracellularly, the Rho/Rho kinase (ROCK) pathway has been suggested to mediate the growth inhibition of CSPGs (Monnier et al., 2003) and myelinassociated inhibitors (Niederöst et al., 2002), and integrin-mediated suppression of the Rho/ROCK pathway is required to promote cell motility (Arthur et al., 2000). Additionally, kindlin-1 (Tan et al., 2012) and full-length talin (Tan et al., 2015) have been shown to promote neurite outgrowth in the presence of CSPGs by binding to $\beta 1$ integrin for integrin activation, resulting in increased integrin signaling via FAK and integrin linked kinase (Schaller et al., 1995; Novak et al., 1998). Kindlins activate integrins by binding to the $\beta$ tail via their FERM domain. They also bind to phosphatidylinositol3,4,5-triphosphate and paxillin (Rognoni et al., 2016; Theodosiou et al., 2016). Full-

length talin cannot be used for promoting neuronal regeneration because of its large size, and the talin head, which contains the integrin-binding and activating site, inhibits axon growth, probably by competing with full-length talin (Tan et al., 2015).

In the present experiments, we expressed $\alpha 9$ integrin, which combines with the pool of $\beta 1$ subunit in adult DRG neurons, to produce $\alpha 9 \beta 1$ integrin, which can then be activated via the inside-out pathway using kindlin-1. Tissue culture experiments using dissociated adult DRG neurons and adult DRGs transduced in vivo showed that $\alpha 9 \beta 1$ integrin promotes growth on tenascin-C, but this growth is inhibited by CSPGs. Activation with kindlin-1 enables the axons to overcome this CSPG inhibition. The same combination of molecules was then transduced into DRG neurons in vivo coupled with dorsal root crush injury. Axons expressing either $\alpha 9$ integrin or kindlin-1 alone showed limited regeneration through the DREZ into the cord, but only the synergistic effect of $\alpha 9$ integrin and kindlin-1 coexpression resulted in a combined effect, which led to much greater axon regeneration, with many axons regenerating seven or more spinal levels to and beyond C1, for a length of up to $25 \mathrm{~mm}$ and above. It will be important to study the regenerative effect of $\alpha 9$ integrin and kindlin-1 coexpression when the injury is placed in the spinal cord rather than the dorsal root. Tenascin-C is strongly upregulated around spinal injuries, so it is probable that axons expressing activated $\alpha 9$ integrin will grow extensively in this environment, as they did through the upregulated tenascin-C at the DREZ in the present study.

It is interesting that kindlin1-only expressing axons were able to grow a limited distance into the spinal cord, whereas kindlin-1 did not increase growth in our in vitro experiments. We assume that this occurs because DRGs express various integrins, such as $\alpha \mathrm{V} \beta 8$ and $\alpha 7 \beta 1$ (Chiu et al., 2014; Tucker and ChiquetEhrismann, 2015), which become activated, allowing them to interact with various integrin ligands in the spinal cord, whereas in the in vitro assay, only tenascin-C and aggrecan were present. These kindlin1-activated integrins were able to produce some axon growth but were relatively ineffective compared with activated $\alpha 9 \beta 1$ integrin.

\section{Long-distance axon regeneration in the spinal cord}

We have demonstrated complete axotomy electrophysiologically and by using two tracers to demonstrate complete denervation of the cuneate nucleus; this was a good control because no axons regenerated back to the cuneate nucleus. We also examined the time course of regeneration, finding regeneration into the DREZ at 3 weeks, to the lower cervical cord at 6 weeks, and to $C 1$ and above at 12 weeks. To date, dorsal column regeneration to the nucleus has only been reported in cases with high cervical lesion and with neurotrophin stimulation (Alto et al., 2009; Bonner et al., 2011) or at a longer experimental time point of up to 6 months after treatment with artemin (Wang et al., 2008; Wong et al., 
A
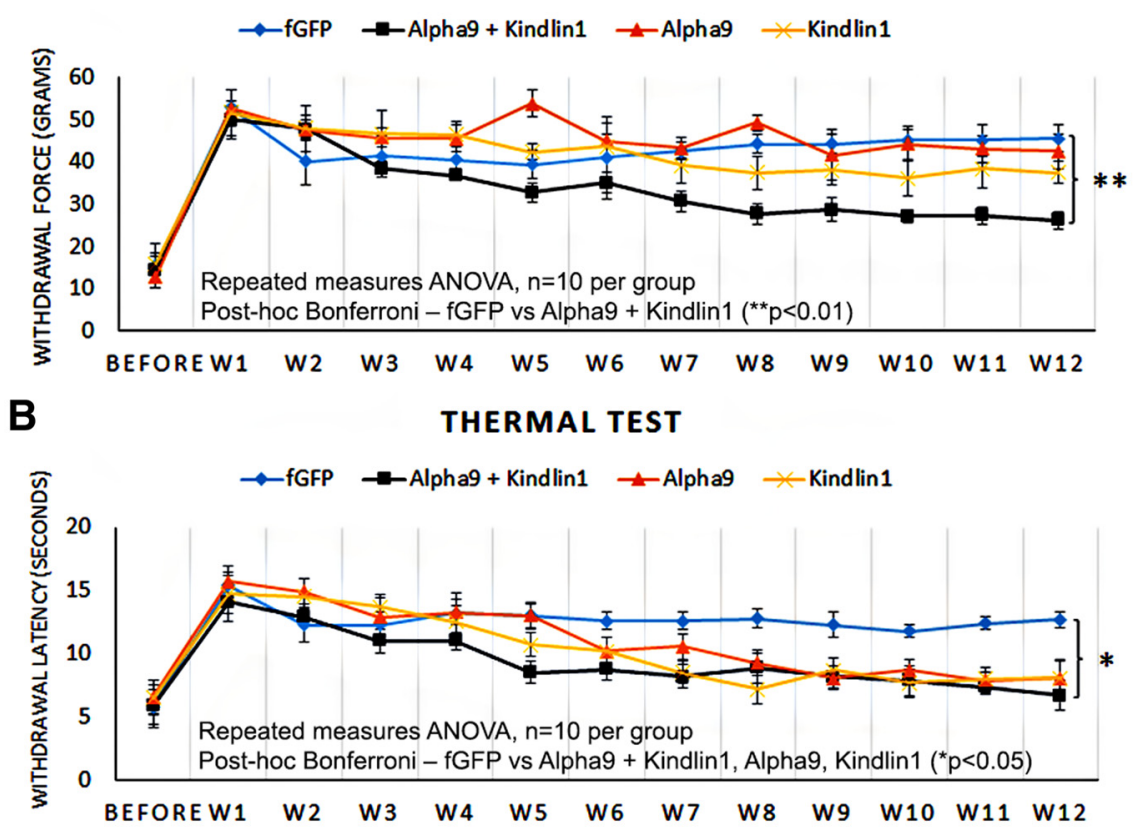

C LADDER RUNG WALKING TASK

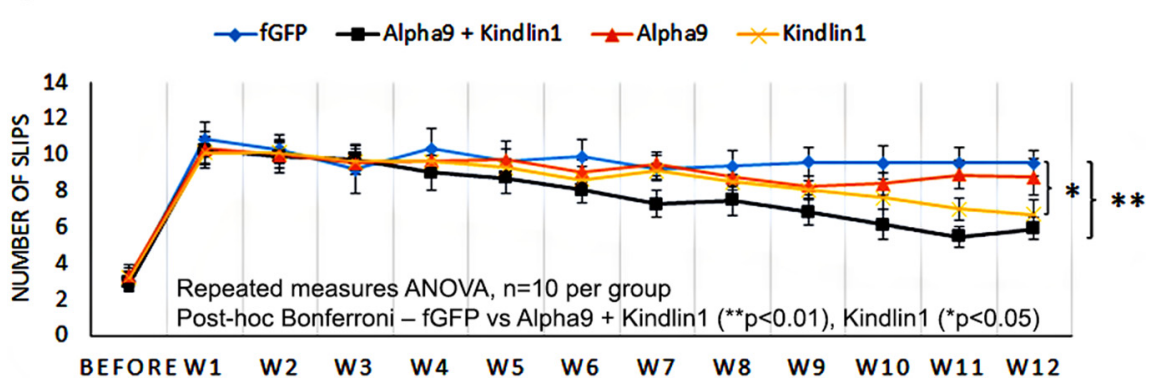

Figure 11. Treatment with $\alpha 9$ integrin and kindlin-1 promotes sensory behavioral recovery. $\boldsymbol{A}-\boldsymbol{C}$, Mechanical pressure test $(\boldsymbol{A})$, thermal test $(\boldsymbol{B})$, and ladder-rung walking task $(\boldsymbol{C})$ on the experimental left forepaw, before the surgery and during weeks 1-12 after surgery. The results were analyzed by repeated-measures ANOVA and expressed as mean \pm SEM. ${ }^{*} p<0.05$ and ${ }^{* *} p<0.01$ were statistically significant, $n=10$ per group.

2015). Combinatorial overexpression of two neuronal intrinsic regeneration-associated genes, GAP43 and CAP23 (Bomze et al., 2001), or four regeneration-associated transcription factors, activating transcription factor 3, c-Jun, signal transducer and activator of transcription 3, and Smad1 (Fagoe et al., 2015), have produced relatively modest sensory axon regeneration. The current approach of combining an integrin with an integrin activator seems to be the most effective strategy to boost the intrinsic regenerative capacity of an injured sensory neuron.

The pathway taken by the regenerating axons was remarkably normal, with most NF200-positive axons traveling in the dorsal column and reinnervation of the dorsal horn by NF200-, CGRP-, and IB4-positive processes being mainly in the correct layers, although less precise than normal. This implies either that some axon guidance information remains in the denervated adult cord and/or that the axons were following the physical pathways of the degenerated axons. We did not see evidence of axonal misguidance or wandering as observed in some recent regeneration experiments (Luo et al., 2013). We suggest that stimulation of regeneration through expression of an appropriate surface receptor allows for normal signaling within the axons, whereas maximal direct activation of signaling pathways might render axons dazzled and unable to see features in their environment.

\section{Behavioral recovery}

Animals receiving treatment of both $\alpha 9$ integrin and kindlin-1 showed good recovery in all three behavioral tests despite no direct reinnervation of the cuneate nucleus. The observation that thermal pain sensation is restored even with the very limited and local reinnervation that we saw in the $\alpha 9$ integrin or kindlin1-alone groups is consistent with the view that heat withdrawal is a local spinal reflex. However, mechanical pressure sensation and ladder-walking proprioception were restored only in those animals treated with both $\alpha 9$ integrin and kindlin-1, suggesting that a more complete reinnervation is required for these behaviors. Although there was no direct reinnervation of the cuneate nucleus, it is possible that propriospinal neurons received input from regenerated axons and then relayed information up to the brain.

The prolific regeneration that we have seen in sensory axons forced to express $\alpha 9$ integrin and kindlin-1 begs the question of whether this strategy could be used to promote regeneration of CNS axons. However, there are problems with this approach. Integrins are transported readily down adult DRG neurons to be inserted into the growth cones (Eva et al., 2010, 2012), explaining how $\alpha 9$ integrin expression can promote dorsal column regeneration, but trafficking of integrins in cortical neuron axons is very different. During developmental growth, cortical neurons transport integrins, but with neuronal maturity integrins become restricted to the somatodendritic domain and are excluded from the axons, hence contributing to the developmental loss of regenerative ability in CNS axons (Heintz et al., 2014; Franssen et al., 2015). Extension of the $\alpha 9$ integrin-kindlin1 approach to CNS axons will require a solution to this issue. However, it is now reasonable to ask whether it would be possible to restore useful sensation to patients with spinal injuries. Restoration of sensation would enable patients to avoid burns, pressure sores, and other damage and to improve manipulative ability. In addition, restoration of genital sensation is a desired outcome for many patients (Anderson, 2004).

\section{References}

Alto LT, Havton LA, Conner JM, Hollis ER 2nd, Blesch A, Tuszynski MH (2009) Chemotropic guidance facilitates axonal regeneration and synapse formation after spinal cord injury. Nat Neurosci 12:1106-1113. CrossRef Medline

Anderson KD (2004) Targeting recovery: priorities of the spinal cordinjured population. J Neurotrauma 21:1371-1383. CrossRef Medline

Andrews MR, Czvitkovich S, Dassie E, Vogelaar CF, Faissner A, Blits B, Gage FH, ffrench-Constant C, Fawcett JW (2009) Alpha9 integrin promotes neurite outgrowth on tenascin- $\mathrm{C}$ and enhances sensory axon regeneration. J Neurosci 29:5546-5557. CrossRef Medline

Arthur WT, Petch LA, Burridge K (2000) Integrin engagement suppresses RhoA activity via a c-Src-dependent mechanism. Curr Biol 10:719-722. CrossRef Medline 
Bomze HM, Bulsara KR, Iskandar BJ, Caroni P, Skene JH (2001) Spinal axon regeneration evoked by replacing two growth cone proteins in adult neurons. Nat Neurosci 4:38-43. CrossRef Medline

Bonner JF, Connors TM, Silverman WF, Kowalski DP, Lemay MA, Fischer I (2011) Grafted neural progenitors integrate and restore synaptic connectivity across the injured spinal cord. J Neurosci 31:4675-4686. CrossRef Medline

Bradbury EJ, Moon LD, Popat RJ, King VR, Bennett GS, Patel PN, Fawcett JW, McMahon SB (2002) Chondroitinase ABC promotes functional recovery after spinal cord injury. Nature 416:636-640. CrossRef Medline

Cafferty WB, Yang SH, Duffy PJ, Li S, Strittmatter SM (2007) Functional axonal regeneration through astrocytic scar genetically modified to digest chondroitin sulfate proteoglycans. J Neurosci 27:2176-2185. CrossRef Medline

Carulli D, Rhodes KE, Brown DJ, Bonnert TP, Pollack SJ, Oliver K, Strata P, Fawcett JW (2006) Composition of perineuronal nets in the adult rat cerebellum and the cellular origin of their components. J Comp Neurol 494:559-577. CrossRef Medline

Carulli D, Pizzorusso T, Kwok JC, Putignano E, Poli A, Forostyak S, Andrews MR, Deepa SS, Glant TT, Fawcett JW (2010) Animals lacking link protein have attenuated perineuronal nets and persistent plasticity. Brain 133:2331-2347. CrossRef Medline

Chiu IM, Barrett LB, Williams EK, Strochlic DE, Lee S, Weyer AD, Lou S, Bryman GS, Roberson DP, Ghasemlou N, Piccoli C, Ahat E, Wang V, Cobos EJ, Stucky CL, Ma Q, Liberles SD, Woolf CJ (2014) Transcriptional profiling at whole population and single cell levels reveals somatosensory neuron molecular diversity. Elife 3. CrossRef Medline

Condic ML (2001) Adult neuronal regeneration induced by transgenic integrin expression. J Neurosci 21:4782-4788. Medline

Ekström PA, Mayer U, Panjwani A, Pountney D, Pizzey J, Tonge DA (2003) Involvement of alpha7beta1 integrin in the conditioning-lesion effect on sensory axon regeneration. Mol Cell Neurosci 22:383-395. CrossRef Medline

Eva R, Dassie E, Caswell PT, Dick G, ffrench-Constant C, Norman JC, Fawcett JW (2010) Rab11 and its effector Rab coupling protein contribute to the trafficking of $\beta 1$ integrins during axon growth in adult dorsal root ganglion neurons and PC12 cells. J Neurosci 30:11654-11669. CrossRef Medline

Eva R, Crisp S, Marland JR, Norman JC, Kanamarlapudi V, ffrench-Constant C, Fawcett JW (2012) ARF6 directs axon transport and traffic of integrins and regulates axon growth in adult DRG neurons. J Neurosci 32: 10352-10364. CrossRef Medline

Fagoe ND, Attwell CL, Kouwenhoven D, Verhaagen J, Mason MR (2015) Overexpression of ATF3 or the combination of ATF3, c-Jun, STAT3 and Smad1 promotes regeneration of the central axon branch of sensory neurons but without synergistic effects. Hum Mol Genet 24:6788-6800. CrossRef Medline

Franssen EH, Zhao RR, Koseki H, Kanamarlapudi V, Hoogenraad CC, Eva R, Fawcett JW (2015) Exclusion of integrins from CNS axons is regulated by Arf6 activation and the AIS. J Neurosci 35:8359-8375. CrossRef Medline

Friedlander DR, Milev P, Karthikeyan L, Margolis RK, Margolis RU, Grumet M (1994) The neuronal chondroitin sulfate proteoglycan neurocan binds to the neural cell adhesion molecules Ng-CAM/L1/NILE and $\mathrm{N}-\mathrm{CAM}$, and inhibits neuronal adhesion and neurite outgrowth. J Cell Biol 125:669-680. CrossRef Medline

Gardiner NJ, Fernyhough P, Tomlinson DR, Mayer U, von der Mark H, Streuli CH (2005) Alpha7 integrin mediates neurite outgrowth of distinct populations of adult sensory neurons. Mol Cell Neurosci 28: 229-240. CrossRef Medline

Gardiner NJ, Moffatt S, Fernyhough P, Humphries MJ, Streuli CH, Tomlinson DR (2007) Preconditioning injury-induced neurite outgrowth of adult rat sensory neurons on fibronectin is mediated by mobilisation of axonal alpha5 integrin. Mol Cell Neurosci 35:249-260. CrossRef Medline

Hammarberg H, Wallquist W, Piehl F, Risling M, Cullheim S (2000) Regulation of laminin-associated integrin subunit mRNAs in rat spinal motoneurons during postnatal development and after axonal injury. J Comp Neurol 428:294-304. CrossRef Medline

Heintz TG, Heller JP, Zhao R, Caceres A, Eva R, Fawcett JW (2014) Kinesin KIF4A transports integrin betal in developing axons of cortical neurons. Mol Cell Neurosci 63:60-71. CrossRef Medline

Hermens WT, ter Brake O, Dijkhuizen PA, Sonnemans MA, Grimm D, Klein- schmidt JA, Verhaagen J (1999) Purification of recombinant adenoassociated virus by iodixanol gradient ultracentrifugation allows rapid and reproducible preparation of vector stocks for gene transfer in the nervous system. Hum Gene Ther 10:1885-1891. CrossRef Medline

Hu F, Strittmatter SM (2008) The N-terminal domain of Nogo-A inhibits cell adhesion and axonal outgrowth by an integrin-specific mechanism. J Neurosci 28:1262-1269. CrossRef Medline

Joester A, Faissner A (1999) Evidence for combinatorial variability of tenascin-C isoforms and developmental regulation in the mouse central nervous system. J Biol Chem 274:17144-17151. CrossRef Medline

Kwok JC, Yang S, Fawcett JW (2014) Neural ECM in regeneration and rehabilitation. Prog Brain Res 214:179-192. CrossRef Medline

Lein PJ, Higgins D, Turner DC, Flier LA, Terranova VP (1991) The NC1 domain of type IV collagen promotes axonal growth in sympathetic neurons through interaction with the alpha 1 beta 1 integrin. J Cell Biol 113:417-428. CrossRef Medline

Lundell A, Olin AI, Mörgelin M, al-Karadaghi S, Aspberg A, Logan DT (2004) Structural basis for interactions between tenascins and lectican C-type lectin domains: evidence for a crosslinking role for tenascins. Structure 12:1495-1506. CrossRef Medline

Luo X, Salgueiro Y, Beckerman SR, Lemmon VP, Tsoulfas P, Park KK (2013) Three-dimensional evaluation of retinal ganglion cell axon regeneration and pathfinding in whole mouse tissue after injury. Exp Neurol 247:653662. CrossRef Medline

Mason MR, Ehlert EM, Eggers R, Pool CW, Hermening S, Huseinovic A, Timmermans E, Blits B, Verhaagen J (2010) Comparison of AAV serotypes for gene delivery to dorsal root ganglion neurons. Mol Ther 18: 715-724. CrossRef Medline

McPhail LT, Borisoff JF, Tsang B, Hwi LP, Kwiecien JM, Ramer MS (2007) Protracted myelin clearance hinders central primary afferent regeneration following dorsal rhizotomy and delayed neurotrophin-3 treatment. Neurosci Lett 411:206-211. CrossRef Medline

Mercado ML, Nur-e-Kamal A, Liu HY, Gross SR, Movahed R, Meiners S (2004) Neurite outgrowth by the alternatively spliced region of human tenascin-C is mediated by neuronal alpha7betal integrin. J Neurosci 24: 238-247. CrossRef Medline

Milev P, Fischer D, Häring M, Schulthess T, Margolis RK, ChiquetEhrismann R, Margolis RU (1997) The fibrinogen-like globe of tenascin-C mediates its interactions with neurocan and phosphacan/ protein-tyrosine phosphatase-zeta/beta. J Biol Chem 272:15501-15509. CrossRef Medline

Monnier PP, Sierra A, Schwab JM, Henke-Fahle S, Mueller BK (2003) The Rho/ROCK pathway mediates neurite growth-inhibitory activity associated with the chondroitin sulfate proteoglycans of the CNS glial scar. Mol Cell Neurosci 22:319-330. CrossRef Medline

Moon LD, Asher RA, Rhodes KE, Fawcett JW (2001) Regeneration of CNS axons back to their target following treatment of adult rat brain with chondroitinase ABC. Nat Neurosci 4:465-466. Medline

Moser M, Legate KR, Zent R, Fässler R (2009) The tail of integrins, talin, and kindlins. Science 324:895-899. CrossRef Medline

Neugebauer KM, Emmett CJ, Venstrom KA, Reichardt LF (1991) Vitronectin and thrombospondin promote retinal neurite outgrowth: developmental regulation and role of integrins. Neuron 6:345-358. CrossRef Medline

Niederöst B, Oertle T, Fritsche J, McKinney RA, Bandtlow CE (2002) Nogo-A and myelin-associated glycoprotein mediate neurite growth inhibition by antagonistic regulation of RhoA and Rac1. J Neurosci 22: 10368-10376. Medline

Novak A, Hsu SC, Leung-Hagesteijn C, Radeva G, Papkoff J, Montesano R, Roskelley C, Grosschedl R, Dedhar S (1998) Cell adhesion and the integrin-linked kinase regulate the LEF-1 and beta-catenin signaling pathways. Proc Natl Acad Sci USA 95:4374-4379. CrossRef Medline

Pasterkamp RJ, Verhaagen J (2006) Semaphorins in axon regeneration: developmental guidance molecules gone wrong? Philos Trans R Soc Lond B Biol Sci 361:1499-1511. CrossRef Medline

Probstmeier R, Pesheva P (1999) Tenascin-C inhibits betal integrindependent cell adhesion and neurite outgrowth on fibronectin by a disialoganglioside-mediated signaling mechanism. Glycobiology 9: 101-114. CrossRef Medline

Probstmeier R, Braunewell K, Pesheva P (2000) Involvement of chondroitin sulfates on brain-derived tenascin- $\mathrm{R}$ in carbohydrate-dependent interac- 
tions with fibronectin and tenascin-C. Brain Res 863:42-51. CrossRef Medline

Rogalski TM, Mullen GP, Gilbert MM, Williams BD, Moerman DG (2000) The UNC-112 gene in Caenorhabditis elegans encodes a novel component of cell-matrix adhesion structures required for integrin localization in the muscle cell membrane. J Cell Biol 150:253-264. CrossRef Medline

Rognoni E, Ruppert R, Fässler R (2016) The kindlin family: functions, signaling properties and implications for human disease. J Cell Sci 129: 17-27. CrossRef Medline

Schaller MD, Otey CA, Hildebrand JD, Parsons JT (1995) Focal adhesion kinase and paxillin bind to peptides mimicking beta integrin cytoplasmic domains. J Cell Biol 130:1181-1187. CrossRef Medline

Staniszewska I, Sariyer IK, Lecht S, Brown MC, Walsh EM, Tuszynski GP, Safak M, Lazarovici P, Marcinkiewicz C (2008) Integrin alpha9 betal is a receptor for nerve growth factor and other neurotrophins. J Cell Sci 121:504-513. CrossRef Medline

Takahashi Y, Nakajima Y (1996) Dermatomes in the rat limbs as determined by antidromic stimulation of sensory C-fibers in spinal nerves. Pain 67:197-202. CrossRef Medline

Tan CL, Kwok JC, Patani R, Ffrench-Constant C, Chandran S, Fawcett JW (2011) Integrin activation promotes axon growth on inhibitory chondroitin sulfate proteoglycans by enhancing integrin signaling. J Neurosci 31:6289-6295. CrossRef Medline

Tan CL, Andrews MR, Kwok JC, Heintz TG, Gumy LF, Fässler R, Fawcett JW (2012) Kindlin-1 enhances axon growth on inhibitory chondroitin sulfate proteoglycans and promotes sensory axon regeneration. J Neurosci 32:7325-7335. CrossRef Medline

Tan CL, Kwok JC, Heller JP, Zhao R, Eva R, Fawcett JW (2015) Full length talin stimulates integrin activation and axon regeneration. Mol Cell Neurosci 68:1-8. CrossRef Medline

Theodosiou M, Widmaier M, Bottcher RT, Rognoni E, Veelders M, Bharadwaj M, Lambacher A, Austen K, Muller DJ, Zent R, Fassler R (2016) Kindlin-2 cooperates with talin to activate integrins and induces cell spreading by directly binding paxillin. Elife 5 . CrossRef Medline

Tucker RP, Chiquet-Ehrismann R (2015) Tenascin-C: its functions as an integrin ligand. Int J Biochem Cell Biol 65:165-168. CrossRef Medline

Ussar S, Wang HV, Linder S, Fässler R, Moser M (2006) The Kindlins: subcellular localization and expression during murine development. Exp Cell Res 312:3142-3151. CrossRef Medline

Vogelezang MG, Liu Z, Relvas JB, Raivich G, Scherer SS, ffrench-Constant C (2001) Alpha4 integrin is expressed during peripheral nerve regeneration and enhances neurite outgrowth. J Neurosci 21:6732-6744. Medline

Wallquist W, Zelano J, Plantman S, Kaufman SJ, Cullheim S, Hammarberg H (2004) Dorsal root ganglion neurons up-regulate the expression of laminin-associated integrins after peripheral but not central axotomy. J Comp Neurol 480:162-169. CrossRef Medline

Wang R, King T, Ossipov MH, Rossomando AJ, Vanderah TW, Harvey P, Cariani P, Frank E, Sah DW, Porreca F (2008) Persistent restoration of sensory function by immediate or delayed systemic artemin after dorsal root injury. Nat Neurosci 11:488-496. CrossRef Medline

Wong LE, Gibson ME, Arnold HM, Pepinsky B, Frank E (2015) Artemin promotes functional long-distance axonal regeneration to the brainstem after dorsal root crush. Proc Natl Acad Sci USA 112:6170-6175. CrossRef Medline

Wu A, Lauschke JL, Morris R, Waite PM (2009) Characterization of rat forepaw function in two models of cervical dorsal root injury. J Neurotrauma 26:17-29. CrossRef Medline 